\title{
Decentralization with porous borders: Public production in a federation with tax competition and spillovers*
}

\author{
Stephanie Armbruster ${ }^{\dagger}$ and Beat Hintermann $\ddagger$
}

August 22, 2019

\begin{abstract}
We analyze the strategic interaction of regional and federal governments using a model that includes fiscal externalities in the form of inter-regional capital tax competition and technical externalities in the form of inter-regional spillovers. The federal government aims to correct for these inefficiencies using a transfer system. If the regional governments are policy leaders (such that federal policy is set conditional on regional choices), they will internalize both fiscal and technical externalities but free-ride on the transfer system. Efficiency can be achieved by introducing a second transfer scheme that is independent of regional public production. If the federal government sets its policy first and can commit itself to it, the outcome is efficient only if matching grants are used that are financed outside of the transfer system.
\end{abstract}

Keywords: Fiscal federalism; tax competition; externalities; spillovers; commitment; centralized leadership; decentralized leadership

JEL codes: H21, H40, H77, Q58

${ }^{*}$ This research has been supported by the Swiss National Science Foundation under grant Nr. CRSII1-154404 (Sinergia).

${ }^{\dagger}$ Address: Peter-Merian-Weg 6, CH-4002 Basel, CH. stephanie.armbruster@unibas.ch

$\ddagger$ Address: Peter-Merian-Weg 6, CH-4002 Basel, CH. b.hintermann@unibas.ch 


\section{Introduction}

Fiscal decentralization is an important feature of modern public finance. In 2014, local governments accounted on average for a third of consolidated government spending in OECD countries, ranging from $7 \%$ in Greece to $69 \%$ in Canada. The most decentralized policy areas are housing and community services, followed by the environment, education, leisure, culture and religion (Blöchliger and Kim, 2016). Decentralization has many advantages ${ }^{1}$ but it can also lead to technical and fiscal externalities. In this paper, we focus on their combined effect by introducing spatial externalities ("spillovers") into a tax competition model. We compute the equilibrium outcome under different assumptions about the commitment ability of the central government, and about the type of available policy instruments.

Some decentrally provided public goods are characterized by inter-regional spillovers, which introduces a scope for horizontal strategic behavior by regional and local governments. Examples for such technical externalities include environmental regulation that also affects neighboring regions, fire protection measures that mitigate the risk of a wildfire spread across jurisdictions, infrastructure projects that can also be used by people who do not pay taxes in the jurisdiction that financed them, or economic-geography effects such as clusters of research and development that could affect growth in nearby regions $2^{2}$ If local governments do not consider the benefit to residents from other jurisdictions, they will under-provide the public good relative to what would be socially optimal (Williams, 1966; Oates, 1999; Wellisch, 1994; Lockwood, 1999; Bloch and Zenginobuz, 2007).

A related yet qualitatively different problem are fiscal externalities, which arise if local governments tax a mobile tax base. For example, when taxing capital employed in a region, local governments tend to ignore the benefit in other regions when they consider a marginal increase in the tax rate that induces a capital outflow, which results in tax rates that are inefficiently low (Zodrow and Mieszkowski, 1986; Wildasin, 1989) ? $^{3}$ A fiscal externality can also

\footnotetext{
${ }^{1}$ Abstracting from interregional spillovers, decentralization can enhance or hinder efficiency depending on the context. Arzaghi and Henderson (2005) measure the determinants and the demand for decentralization in different contexts. From a political economy point of view, the principal (voters) can control the performance of the agent (government) better if the latter is local, which can lead to a better government performance and increased happiness (Voigt and Blume, 2012).

${ }^{2}$ Spillovers can consist of public goods produced in one jurisdiction "spilling out" to other jurisdictions (e.g., flood protection measures that also protect jurisdictions located downriver), or the population of other jurisdictions "spilling into" a jurisdiction to consume a public good good (e.g., the visiting a subsidized opera house or sports stadium).

${ }^{3}$ See Wilson and Wildasin (2004), Fuest et al. (2005) and Keen and Konrad (2013) for comprehensive surveys
} 
arise in the context of residence-based tax competition (typically, such taxes apply to property or income), in which households do not consider their fiscal impact on others when moving to a jurisdiction; for a review, see Brlhart et al. (2015).

Some previous models have combined technical and fiscal externalities into a single framework. Bjorvatn and Schjelderup (2002) show that in the presence of (positive) spillovers, the inefficiency from inter-regional capital tax competition is mitigated, and Kuhlmey and Hintermann (2019) find qualitatively similar results in the context of tax-induced Tiebout sorting. The underlying intuition is that a share of the tax base that relocated to other regions "spills back" into the home jurisdiction in the form of public consumption. Although technical and fiscal externalities can exactly offset each other in special cases (see, e.g., Pinto, 2007; Eichner and Runkel, 2012; Ogawa and Wildasin, 2009), the coexistence of both types of externalities is generally associated with an inefficient outcome Oates and Schwab, 1988; Fell and Kaffine, 2014). In a model that uses labor as the mobile factor (rather than capital as in this paper and most of the literature), Bloch and Zenginobuz (2015) show that the inefficiency of decentralization increases both with the degree of spillovers and the mobility of the population.

Most of the articles about tax competition use an international setting in which regions compete against each other in the absence of a central government. In a federalist system, the central government can address inefficiencies and redistributive concerns among regions by means of corrective policies such as transfers and grants. However, federal transfers may cause new distortions, especially if the central government is unable to commit to its policies 4 A lack of federal commitment can be modeled using a Stackelberg game, in which local governments act as leaders and the central government as a follower, which has given rise to the term "decentralized leadership" (Silva and Caplan, 1997). This is closely related to the literature concerned with "soft" budget constraints $5^{5}$ In contrast, if the federal government can commit to its policy, this is referred to "centralized leadership". Federal commitment is often implicitly on capital taxation.

${ }^{4}$ There are economic and political arguments for an inability to commit on behalf of the central government. If the central government is benevolent and interested in maximizing total welfare, it might change from its pre-specified policy if inefficiencies from local policy decisions are too large (Wildasin, 1999). Political motives include reputation effects and the incentives to win votes by giving transfers to poorer regions (see Oates, 2005).

${ }^{5}$ Some of the literature labels the lack of commitment inability as a "soft budget constraint" (see Qian and Roland, 1998; Goodspeed, 2002; Kornai et al., 2003). A soft budget constraint implies that the central government is expected to increase subsidies in response to regional government taxes as it allocates these grants in order to equalize marginal utilities of public good consumption across the federation. See Kornai et al. (2003) for a more in-depth discussion of soft budget constraints. 
assumed when analyzing corrective policies (see, e.g., Wildasin, 1989, DePeter and Myers, 1994: Dahlby, 1996; Wilson and Wildasin, 2004; Ogawa, 2006). Empirical evidence for whether the federal government can or cannot commit is inconclusive (see, e.g., Hayashi and Boadway, 2001), and the reality often lies between these polar cases: Although we do observe that central governments "bail out" regions or member states, marginal public consumption is arguably not equalized within federations, as would be predicted under a model of decentralized leadership. Besides assumptions regarding commitment, the efficiency implications of a federal transfer scheme depend on its specific form. Boadway (2004) differentiates federal transfers into two broad categories: A "gross" scheme is characterized by transfers from the federal government to the regions financed by a central tax, whereas a "net" scheme is self-financing in the sense that it only consists of inter-regional transfers that must add up to zero.

In this paper, we analyze the interplay of technical and fiscal spillovers under both centralized and decentralized leadership and different federal transfer systems. We investigate the conditions under which the social optimum can be implemented, and the sensitivity of the outcome with respect to the strength of inter-regional spillovers. Whereas some of the results we derive have been previously reported, others are new to the literature, and we present them in a series of propositions. Furthermore, by comparing the different outcomes within a single framework, we facilitate a comparison and synthesis of the possible outcomes, and thus increase our knowledge of the efficiency aspects of transfer schemes that aim to support public production within a federation.

A number of previous papers have addressed the efficiency of decentralized public provision in the context of strictly local public goods (Koethenbuerger, 2004; Breuille et al., 2010; Silva, 2016). Caplan et al. (2000) investigate the special case of a public good that is associated with perfect spillovers (which makes it a "global" public good) and prove that under decentralized leadership and a net transfer scheme, the outcome can be efficient. As shown by Akai and Sato (2008), the efficiency property hinges on the assumption of perfect spillovers. Throughout the paper, we allow for the entire range between zero and perfect spillovers, and our results therefore include those of Koethenbuerger (2004) and Caplan et al. (2000) as special cases. We focus on public goods that convey a positive externality and thus abstract from situations where public production negatively affects utility in neighboring jurisdictions ${ }^{6}$

Bondarev et al. (2017) examine the choice between different types of public goods, some of which may 
Our paper shows that the efficiency of the outcome crucially depends on the federal commitment ability and the available transfer system. Several results emerge from the paper. We find that an inability to commit on behalf of the central government leads regions to free-ride on the tax revenue of other regions via the federal transfer scheme, but that spillovers to other regions are internalized by the regional governments when they optimize their public production. Intuitively, regions anticipate that the federal government will redistribute to the point where public consumption is equalized, conditional on inter-regional spillovers, such that regions cannot make themselves better off by under-providing the public good. If spillovers are perfect in a decentralized leadership setting, no transfers are required to reach an efficient outcome. A net equalizing transfer system complemented with private income redistribution equips the federal government with an additional instrument. This can counteract the free-riding on federal transfers, as in Silva (2016). Since both private and public consumption are equalized ex post by the federal government, the regional governments have an incentive to optimally tax capital. In a gross transfer scheme, the federal government has two instruments as well which ensures optimal public good provision. It does not matter for efficiency, if the federal tax is individualized or uniform. However, with a uniform federal head tax, transfers are completely financed by federal transfers whereas with an individualized federal tax, regional governments set the optimal tax in line with a net equalizing transfer system complemented with private income redistribution.

If the federal government can commit and uses a net transfer system, the solution is characterized by the (inefficient) Nash equilibrium first derived by Bjorvatn and Schjelderup (2002). In this situation, spillovers mitigate the inefficiency due to tax competition, but they lead to free-riding on inter-regional public production. Efficiency can be restored by introducing a matching grant, as shown by Ogawa (2006). However, this necessarily requires a separate source of revenue for the federal government, as the matching grant itself cannot be self-financing.

The paper is organized as follows: In section 2, we present our framework. The Paretooptimal provision of public goods and the Nash equilibrium is rewiewed in Section 3. Section 4 contains our main results, first for the case of decentralized leadership, and second with the roles reversed. The last section concludes.

convey negative externalities to other regions; however, they abstract from tax competition and thus from fiscal externalities. 


\section{Model}

We model a competitive equilibrium describing a two-layer federalist economy, in which regional governments raise revenue and provide public goods. Our model is based on the capital tax competition models of Zodrow and Mieszkowski (1986), Wilson (1986) and Hoyt (1991). We allow the public good to "spill" into other regions in the sense that the public good produced in region $i$ is consumed also in region $j \neq i$. There is no rivalry in consumption. 7 The effect of spillovers in the presence of capital tax competition has previously been analyzed by Bjorvatn and Schjelderup (2002). We extend their "international" model by adding a federal government, and by allowing for sequential policy setting rather than restricting it to be simultaneous.

There are $n \geq 2$ regions $(i, j=1, \ldots, n$ with $i \neq j)$. Each region contains a representative household with identical preferences and an identical endowment of capital and labor. Each region also contains one representative firm. These firms behave perfectly competitively and use identical production technologies. The local governments choose their policies to maximize the utility of the regional household. One federal government exists with the power to enforce transfers between the regions and, in some settings, has the ability to raise revenue via a lumpsum tax. Throughout the text, we use the terms "regional" and "local" interchangeably to refer to the lower level of government and "central" or "federal" to refer to the upper level.

Capital is a productive factor that is mobile across regions, and regional governments tax it to finance their expenditure $\mathrm{g}^{8}$ In addition, production relies on labor $L_{i}$, which is immobile and cannot be taxed by the regional governments.9 Households and firms act as price takers and meet on the factor and consumption good markets. We normalize consumer prices by choosing private consumption as the numeraire.

\footnotetext{
${ }^{7}$ For an analysis focusing on both spillovers and congestion, see Kuhlmey and Hintermann (2019).

${ }^{8}$ Capital is interpreted as physical capital (i.e. factories) and not as financial investments, which would require a different type of model (in which the level of regional production would not depend on the level of capital). Generally speaking, capital is interpreted as anything generating real output that is mobile across regions; see Keen and Konrad (2013) for a discussion. We further refrain from modeling mobility costs of capital.

${ }^{9}$ An alternative interpretation of $L_{i}$ would be land. The relevant assumption about this factor is immobility across regions and that it does not serve as a regional tax base.
} 


\subsection{Private production}

The representative firm within each region produces one good, using capital and labor as inputs. To simplify notation, we normalize production such that $k_{i}$ refers to capital per unit of $L_{i}$. The production function is continuously differentiable and strictly quasi-concave in $k_{i}$, i.e., $f^{\prime}(\cdot)>0>f^{\prime \prime}(\cdot)$. Capital is rented at the (federal) capital market price $R$ and locally taxed at $t_{i}$, and labor is paid wage $w_{i}$.

The profit-maximization problem of the representative firm in region $i$ is given by

$$
\max _{k_{i} \geq 0} f\left(k_{i}\right)-\left(R+t_{i}\right) k_{i}-w_{i} \quad \forall i \in n
$$

Optimal production is characterized by

$$
R+t_{i}=\frac{\partial f\left(k_{i}\right)}{\partial k_{i}}
$$

which implicitly defines the capital demand $k_{i}\left(R+t_{i}\right)$ showing that the marginal products of capital has to equal the price in terms of output.

Under perfect competition and constant returns to scale, revenue is fully exhausted for factor payments such that profits in equilibrium are zero. This determines the equilibrium compensation for $L_{i}$ (if this is labor, then $w_{i}$ is the wage):

$$
w_{i}=f\left(k_{i}\right)-\frac{\partial f\left(k_{i}\right)}{\partial k_{i}} k_{i}
$$

\section{$2.2 \quad$ Public production}

Regional governments have authority over tax collection and public good provision, and they care about the utility of their residents only. Regional governments demand the produced good, which is transformed into a local public good $g_{i}$ for their residents, i.e., they use a domestic production technology which permits to produce one unit of the public good from one unit of the consumption good $c_{i}$ such that $f\left(k_{i}\right)=c_{i}+g_{i}{ }^{10}$ Public goods are financed by a source-based

\footnotetext{
${ }^{10}$ This means that the marginal rate of transformation between the private and the public good is equal to one.
} 
tax on capital and the federal transfer $s_{i}$ :

$$
g_{i}=t_{i} k_{i}+s_{i}
$$

The benevolent federal government implements a transfer system which can either be selffinancing (net transfer system) or financed by an additional federal tax (gross transfer system). Regions count equally for overall welfare. With a net transfer system, transfers to one region are financed by the negative transfers of other regions: ${ }^{11}$

$$
\sum_{i=1}^{n} s_{i}=0 .
$$

The federal government can additionally be equipped with an explicit net transfer system for income (as in Silva, 2016) defined by

$$
\sum_{i=1}^{n} \tau_{i}=0
$$

where $\tau_{i}$ is a lump-sum tax or transfer that applies to region $i$. Note that any symmetric equilibrium under a net transfer system will be characterized by $s_{i}=\tau_{i}=0 \forall i$.

With a gross transfer system, regional transfers are financed by a uniform federal lump-sum tax $T$ on private consumption:

$$
\sum_{i=1}^{n} s_{i}=n T .
$$

\subsection{Market clearing}

Public and private consumption are different uses of the same good and all after-tax income is spent on private demand. The consumption good may be traded across regions. Market clearing

\footnotetext{
${ }^{11}$ Whether the individual transfers add to zero or some other value is immaterial, as long as this value is fixed. The crucial point is that $\sum_{i} d s_{i}=0$ such that increasing the transfer to one reason requires a reduction in the transfers for other regions; for a more general treatment with positive (but fixed) transfers, see Breuille et al. (2010).
} 
requires that the output produced equals the demand for public and private consumption: ${ }^{12}$

$$
\sum_{i=1}^{n} f\left(k_{i}\right)=\sum_{i=1}^{n}\left(g_{i}+c_{i}\right)
$$

Firms in region $i$ demand capital $k_{i}$ and households offer their capital endowment $\bar{k}_{i}$ on the federal market. Total aggregated capital supply $\sum_{i=1}^{n} \bar{k}_{i}=\bar{K}$ is fixed at the federal level. ${ }^{13}$ In the free-trade equilibrium, capital endowed equals capital employed:

$$
\sum_{i=1}^{n} k_{i}=\bar{K}
$$

We restrict our attention to the case where the price for capital is always positive and capital is thus fully employed 14 The capital tax of local governments increases firms' rental price for capital to $R+t_{i}$. In equilibrium, the net return on capital determined by aggregated factor market clearing has to hold in every region due to arbitrage:

$$
R=f^{\prime}\left(k_{i}\right)-t_{i}=f^{\prime}\left(k_{j}\right)-t_{j}>0 \quad \forall \quad i, j
$$

\subsection{Comparative static effects under symmetry}

Adopting the perspective of a specific region $i$ and assuming the other regions to be identical, a static analysis with respect to region $i$ 's tax rate describes the general equilibrium structure of the economy. Differentiating (8) with respect to $t_{i}$ yields:

$$
\frac{\partial \bar{K}}{\partial t_{i}}=\frac{\partial k_{i}}{\partial t_{i}}+(n-1) \frac{\partial k_{j}}{\partial t_{i}}=0, \quad \text { such that } \frac{\partial k_{j}}{\partial t_{i}}=-\left(\frac{1}{n-1}\right) \frac{\partial k_{i}}{\partial t_{i}}
$$

The reaction of the capital price in response to region $i$ 's capital tax rate is derived by

\footnotetext{
${ }^{12}$ With a perfectly competitive product market, condition 77 is always satisfied with identity. To see this, substitute (1) and (2) into the LHS of (7), and substitute (3), (4) and (12) into the RHS, to get $\sum_{N} w_{i}+t_{i} k_{i}+$ $R k_{i}=\sum_{N} w_{i}+t_{i} k_{i} R \bar{k}_{i}$. Since the sum of the employed capital $\left(k_{i}\right)$ has to equal the sum of available capital $\left(\bar{k}_{i}\right)$, the equilibrium condition (7) is always satisfied and can be ignored. Wilson (1987) modifies the model and analyzes trade in two goods; for a modification with trade costs, see Becker and Runkel (2012).

${ }^{13}$ With a fixed capital supply (zero elasticity of supply), impacts of taxes are entirely felt by the aggregated suppliers of capital ( $=$ all households) as $R$ will respond to changes in $t$. Papers relaxing the assumption of fixed capital supply include Ogawa and Wildasin (2009) and Eichner and Runkel (2012).

${ }^{14}$ It is never a dominant strategy for region $i$ to raise its tax until $R=0$, and we abstract from the possibility that capital could be in excess supply, as in Bucovetsky (1991).
} 
differentiating (9):

$$
\frac{\partial R}{\partial t_{i}}=f^{\prime \prime}\left(k_{i}\right) \frac{\partial k_{i}}{\partial t_{i}}-1=f^{\prime \prime}\left(k_{j}\right) \frac{\partial k_{j}}{\partial t_{i}}<0
$$

Combing and imposing symmetry (i.e. $k_{i}=k_{j} \equiv k$ ) leads to the equilibrium conditions previously identified by Koethenbuerger (2004):

$$
\frac{\partial k_{i}}{\partial t_{i}}=\left(\frac{n-1}{n}\right) \frac{1}{f^{\prime \prime}(k)}<0, \quad \frac{\partial k_{j}}{\partial t_{i}}=-\frac{1}{n} \frac{1}{f^{\prime \prime}(k)}>0, \quad \text { and } \quad \frac{\partial R}{\partial t_{i}}=-\frac{1}{n}<0 .
$$

The set of equations 10 shows that there are two consequences to a change region $i$ 's tax rate: The region's own capital demand is reduced, whereas the capital employed in other regions increases via the decrease in the federal interest rate. The latter decreases with the number of regions in the model. Intuitively, if region $i$ increases its tax rate, capital moves out of region $i$ and flows into the other regions $j \neq i$ until the marginal product of capital in all regions is equal to the sum of the regional capital tax rate and the federal interest rate, $R$ (eq. 9.).

\subsection{Consumption by households}

The representative household in each region $i$ obtains utility from private and public consumption, which, in general, also depends on the public goods provided by other regions:

$$
G_{i}=g_{i}+\beta \sum_{\substack{m=1 \\ m \neq i}}^{n} g_{m} \quad \forall i, \quad \beta \in[0,1]
$$

The case $\beta=1$ represents the situation of perfect spillovers ("federal" public good), whereas $\beta=0$ is the case of publicly provided private goods that has been the focus of most of the previous literature. There is no congestion in public consumption.

$U_{i}\left(c_{i}, G_{i}\right)$ is strictly increasing, concave and satisfies the Inada conditions. Households receive income $I_{i}$ from capital endowment and fixed labor supply, which is entirely spent on private consumption:

$$
c_{i}=I_{i} \equiv w_{i}+\bar{k}_{i} R+\tau_{i}-T
$$

where $\tau_{i} \neq 0$ if there is a net transfer system for private income and $T>0$ if there is a gross transfer system. If the federal government uses a net transfer system without additional income 
redistribution, then $\tau_{i}$ and $T$ are both zero.

\section{Benchmark cases}

In this section, we derive the outcome for the social optimum and the Nash equilibrium for symmetric regions, two benchmark cases that have been considered in the previous literature. Although our model contains a federal government, the benchmark results are identical to those derived by Bjorvatn and Schjelderup $(2002)$ in the absence of a federal government ${ }^{15}$ and we therefore keep the exposition brief.

\subsection{Social optimum}

To characterize the set of Pareto-optimal allocations, we use a model in which the federal government acts as a benevolent social planner. It chooses $c_{i}$ and $g_{i}$ to maximize the welfare in the federation, based on a utilitarian social welfare function, by solving: ${ }^{16}$

$$
\begin{aligned}
\max _{\left\{c_{1 \ldots n}\right\},\left\{G_{1 \ldots n}\right\},\left\{g_{1 \ldots n}\right\}} & \sum_{i=1}^{n} U_{i}\left(c_{i}, G_{i}\right) \quad \text { s.t. } \quad G_{i}=g_{i}+\beta \sum_{\substack{m=1 \\
m \neq i}}^{n} g_{m} \\
& \sum_{i=1}^{n} f\left(k_{i}\right)=\sum_{i=1}^{n}\left(c_{i}+g_{i}\right) .
\end{aligned}
$$

Imposing symmetry, defining the marginal rate of substitution between public and private consumption as $M R S_{i} \equiv \frac{\partial U_{i}}{\partial G_{i}} / \frac{\partial U_{i}}{\partial c_{i}}$ and suppressing the subscript yields (for the intermediate steps, refer to the Appendix A.1):

$$
M R S_{i}^{P O}=\frac{1}{1+(n-1) \beta} \quad \forall i
$$

This implicitly defines the optimal tax rate $t^{P O}$. Condition (14) states that a marginal decrease in public consumption requires an increase of $\frac{1}{1+(n-1) \beta}$ in terms of private marginal

\footnotetext{
${ }^{15}$ If regions are not symmetric, the presence of a federal government affects the equilibrium outcome due to the (nonzero) transfer that will co-determine consumption and production. However, the functional forms of the optimality conditions would remain the same. In the social optimum, this is due to the fact that our benevolent federal government simply takes the place of the social planner in Bjorvatn and Schjelderup (2002). For the Nash equilibrium, any federal transfer is considered as given by the regional governments and thus drops out of the first-order conditions.

${ }^{16}$ Because we focus on interior solutions, we abstract from the complementary slackness conditions. The second-order conditions are negative and therefore consistent with a welfare maximum.
} 
consumption in order for utility to remain constant. Without spillovers $(\beta=0)$, the optimal tax is set such that the MRS equates the marginal rate of transformation $(M R T=1)$ between the public good and the private good in production. With $\beta=1$, this collapses to the standard Samuelson rule given by $\sum_{i=1}^{n} M R S_{i}=M R T$.

To gain more intuition, we assume that the federal government uses a self-financing transfer according to (4) and specify the following utility function:

$$
U_{i}\left(c_{i}, G_{i}\right)=\ln \left(c_{i}\right)+\ln \left(\left[t_{i} k_{i}+s_{i}\right]+\beta \sum_{\substack{m=1 \\ m \neq i}}^{n}\left[t_{m} k_{m}+s_{m}\right]\right) .
$$

If regions are symmetric, the self-financing transfer scheme is $s_{i}=0 \forall i$ in equilibrium. Taking the derivative of (15) with respect to $c_{i}$ and $G_{i}$, substituting into (14) and solving for $t_{i}$ leads to the Pareto-optimal tax

$$
t^{P O}=c / k
$$

Note that (16) depends on the model parameters via equilibrium consumption $c$, which is a function of $\beta, n, \bar{K}$ and the parameters of the production function 17

\subsection{Nash Equilibrium}

The second benchmark is the Nash equilibrium, in which the regional and federal governments make their policy choices simultaneously (and cannot adjust them later). We assume that regional governments optimize over taxes and that expenditures adjust residually after transfers are received ${ }^{18}$ The game can be separated into 2 stages. In the first stage, regional governments

\footnotetext{
17 Bjorvatn and Schjelderup (2002) and Koethenbuerger (2004) use a quasi-linear utility function defined by $U_{i}\left(c_{i}, G_{i}\right)=c_{i}+\ln \left(\left[t_{i} k_{i}+s_{i}\right]+\beta \sum_{m \neq i}^{n}\left[t_{m} k_{m}+s_{m}\right]\right)$. Using this in 14 and solving leads to the Paretooptimal tax $t^{P O}=1 / k$, which is independent of $\beta$ and $n$. However, this is due to the fact that the marginal utility of income is constant with quasi-linear preferences, which is obviously a special case.

${ }^{18}$ Akai and Sato (2008) provide a comparison of expenditure and tax optimization in a decentralized leadership game. Our setting, as well as that in Koethenbuerger (2004), Breuille et al. (2010) and Silva (2016) relate to their scenario B, in which $t_{i}$ is decided ex-ante and $g_{i}$ adjusts ex-post. They find that a decentralized leadership system in which taxes are the strategic choice variable leads to revenue-sharing due to local government's freeriding on tax collection efforts of others, in line with Koethenbuerger (2004) and our own results. In contrast, when $g_{i}$ the choice variable, cost-sharing of expenditures leads to excessive expansion i.e. over-provision. The intuition is that choosing $g_{i}$ leads to cost sharing of own expenditure with all other local governments (hence a common pool problem). Ex post per capita transfers to regional governments are increasing in its expenditure and decreasing when other regions spend more. As the ex post tax burden of each regional government depends only on the economy-wide resource constraint, not on its own ex ante spending decisions. Akai and Sato (2008) demonstrate that this fosters overspending ex ante. See Wildasin (1988) for a further discussion on how the choice of strategic variable can influence the Nash equilibrium. In this paper, we focus on regions setting $t_{i}$.
} 
choose local taxes $t_{i}$ to maximize the utility of representative households. In this benchmark scenario, the federal government implements a net transfer system (4), i.e., it chooses a lumpsum transfer system $s_{i}$. All actors take the actions of the others as given and incorporate the behavior of households and firms affected by their decision. In the second stage, firms determine the demand for capital $k_{i}$, produce output. Public production $g_{i}$ adjusts residually, and public and private consumption takes place. Because this stage involves no policy choice, we can suppress it in the analysis. The federal government's maximization problem can be written as follows:

$$
\begin{aligned}
\max _{\left\{c_{1 \ldots n}\right\},\left\{G_{1 \ldots n}\right\},\left\{s_{1 \ldots n}\right\}} & \sum_{i=1}^{n} U\left(c_{i}, G_{i}\right) \\
\text { s.t. } & G_{i}=t_{i} k_{i}+s_{i}+\beta \sum_{\substack{m=1 \\
m \neq i}}^{n} t_{m} k_{m}+s_{m} \\
& \sum_{i=1}^{n} s_{i}=0 \\
& c_{i}=f\left(k_{i}\right)-\frac{\partial f\left(k_{i}\right)}{\partial k_{i}} k_{i}+\bar{k}_{i} R
\end{aligned}
$$

The optimality conditions are given by:

$$
U^{\prime}\left(G_{i}\right)+\beta \sum_{\substack{m=1 \\ m \neq i}}^{n} U^{\prime}\left(G_{m}\right)=U^{\prime}\left(G_{j}\right)+\beta \sum_{\substack{m=1 \\ m \neq j}}^{n} U^{\prime}\left(G_{m}\right) \quad \forall i, j .
$$

If regions are identical, these conditions simplify to:

$$
U^{\prime}\left(G_{i}\right)=U^{\prime}\left(G_{j}\right) \quad \Rightarrow \quad G_{i}=G_{j} \quad \forall i, j
$$

This condition states that public consumption is equalized across regions ${ }^{19}$ From symmetry, equations (19) and (4) imply that $s^{N E}=\left(\frac{n-1}{n}\right)\left(t_{i} k_{i}-t_{j} k_{j}\right)$, which is zero if all regions are identical 20

\footnotetext{
${ }^{19}$ We would like to note that the equalization of public consumption is not the goal but a byproduct of utility maximization. Transfers are chosen with the aim to maximize social welfare, and under symmetry, equalized public consumption is implied.

${ }^{20}$ In symmetry, taxes are equal and consequently capital such that $s^{N E}$ is zero.
} 
The maximization problem faced by the regional governments is:

$$
\begin{aligned}
\max _{G_{i}, g_{i}, c_{i}, t_{i}} U\left(c_{i}, G_{i}\right) \quad \text { s.t. } \quad G_{i} & =g_{i}+\beta \sum_{\substack{m=1 \\
m \neq i}}^{n} g_{m} \\
g_{i} & =t_{i} k_{i}+s_{i} \\
c_{i} & =f\left(k_{i}\right)-f^{\prime}\left(k_{i}\right) k_{i}+\bar{k}_{i} R .
\end{aligned}
$$

Solving this problem, imposing symmetry and using the capital market clearing conditions (10) leads to the optimality condition given by (derivation in Appendix A.1)

$$
M R S^{N E}=\frac{1}{1-(1-\beta) \epsilon},
$$

with $\epsilon \equiv-\frac{\partial k_{i}}{\partial t_{i}} \frac{t_{i}}{k_{i}}=\frac{n-1}{n} \frac{1}{-f^{\prime \prime}(k)} \frac{t}{k}>0$ representing the elasticity of region $i$ 's capital demand with respect to the tax rate. Because regions take the federal transfer as given in the Nash game, $s_{i}$ drops out of the first-order conditions, thus yielding the same result as in Bjorvatn and Schjelderup (2002), where independent regions compete for a tax base in the absence of a federal government.

Using the utility function in (15), substituting into the left-hand side of (21) and solving for the resulting tax rate yields

$$
\begin{aligned}
& t^{N E}=t^{P O} \frac{1}{\left[1+D^{N E}\right]} \\
& D^{N E} \equiv \beta(n-1)+(1-\beta)\left(\frac{n-1}{n}\right) \frac{1}{-f^{\prime \prime}(k)} \frac{1}{k^{2}}>0 .
\end{aligned}
$$

The Nash equilibrium tax $t^{N E}$ is inefficiently low for $n>1$. The expression for the distortionary term $D^{N E}$ illustrates that the inefficiency stems from a convex combination of free-riding and capital tax competition. Without spillovers, $D_{\beta=0}^{N E}=\left(\frac{n-1}{n}\right) \frac{1}{-f^{\prime \prime}(k)} \frac{1}{k^{2}}$ isolates the inefficiency due to the fiscal externality. The fiscal externality arises because regions consider the capital outflow out of their region as a cost when setting their tax rates, but fail to consider benefits accruing to other regions (see also Zodrow and Mieszkowski, 1986; Wilson, 1985, 1986).

If spillovers are present, a $\beta$-fraction of the capital outflow spills back to region $i$ in the form of higher public good provision in the other regions. This is taken into account by region 
$i$ when setting its tax rate. The response of the distortion to a marginal change in the level of spillovers is given by:

$$
\frac{\partial D_{\beta>0}^{N E}}{\partial \beta}=(n-1)\left(1+\frac{1}{n} \frac{1}{f^{\prime \prime}(k)} \frac{1}{k^{2}}\right) .
$$

If $\frac{1}{n} \frac{1}{\left|f^{\prime \prime}(k)\right|} \frac{1}{k^{2}}>1$, an increase of the spillover intensity decreases the distortion relative to the Pareto-optimal tax. Intuitively, if $\left|f^{\prime \prime}\right|$ is small, then a marginal change in the tax rate leads to a relatively large outflow of capital in order to restore the equality $t_{i}+f^{\prime}=R$, whereas if $\left|f^{\prime \prime}\right|$ is large, the corresponding capital outflow is small. If tax competition (the second term in (23)) dominates the welfare loss, an increase in the level of spillovers improves efficiency because this counteracts the fiscal externality. In contrast, if free-riding (the first term in (23)) is relatively more important, then an increase in $\beta$ reduces efficiency.

Note that the Nash result is qualitatively similar to Bloch and Zenginobuz $(2015)$, who model labor as an imperfectly mobile tax base and allow for inter-regional spillovers of the public good. They find that the equililbrium tax rate is non-monotonic in the spillover parameter ${ }^{21}$

\section{Sequential policy setting}

The Nash game gives valuable insights. However, in practice it is often the case that one level of government can observe the decision of the other before making its own choice. We distinguish between the polar cases of decentralized and centralized leadership, which we analyze in turn. Within these cases, we derive the outcomes for different transfer systems available to the federal government: (i) Gross vs. net systems; (ii) with and without additional redistribution of private income; and (iii) lump-sum vs. matching grant. Figure 1 provides an overview of the cases that we study. While some of the results in this section have been previously reported in the literature (shaded boxes), other combinations are new (clear boxes).

\footnotetext{
${ }^{21}$ We refer to Bloch and Zenginobuz $(2015)$, proposition 3. The equilibrium tax rate in their model depends nonlinearly on the spillover parameter, as is the case here. Furthermore, the equilibrium tax rate decreases if mobility increases, which is conceptually similar to the tax in the Nash equilibrium defined by (22)-(23). Here, the tax decreases if capital is "more mobile", meaning that $\left|f^{\prime \prime}\right|$ is smaller (the more linear the production function, the greater is the elasticity of regional capital demand with respect to the tax rate, $\epsilon$ ).
} 
Figure 1: Overview of policy scenarios of capital tax competition with public good spillovers

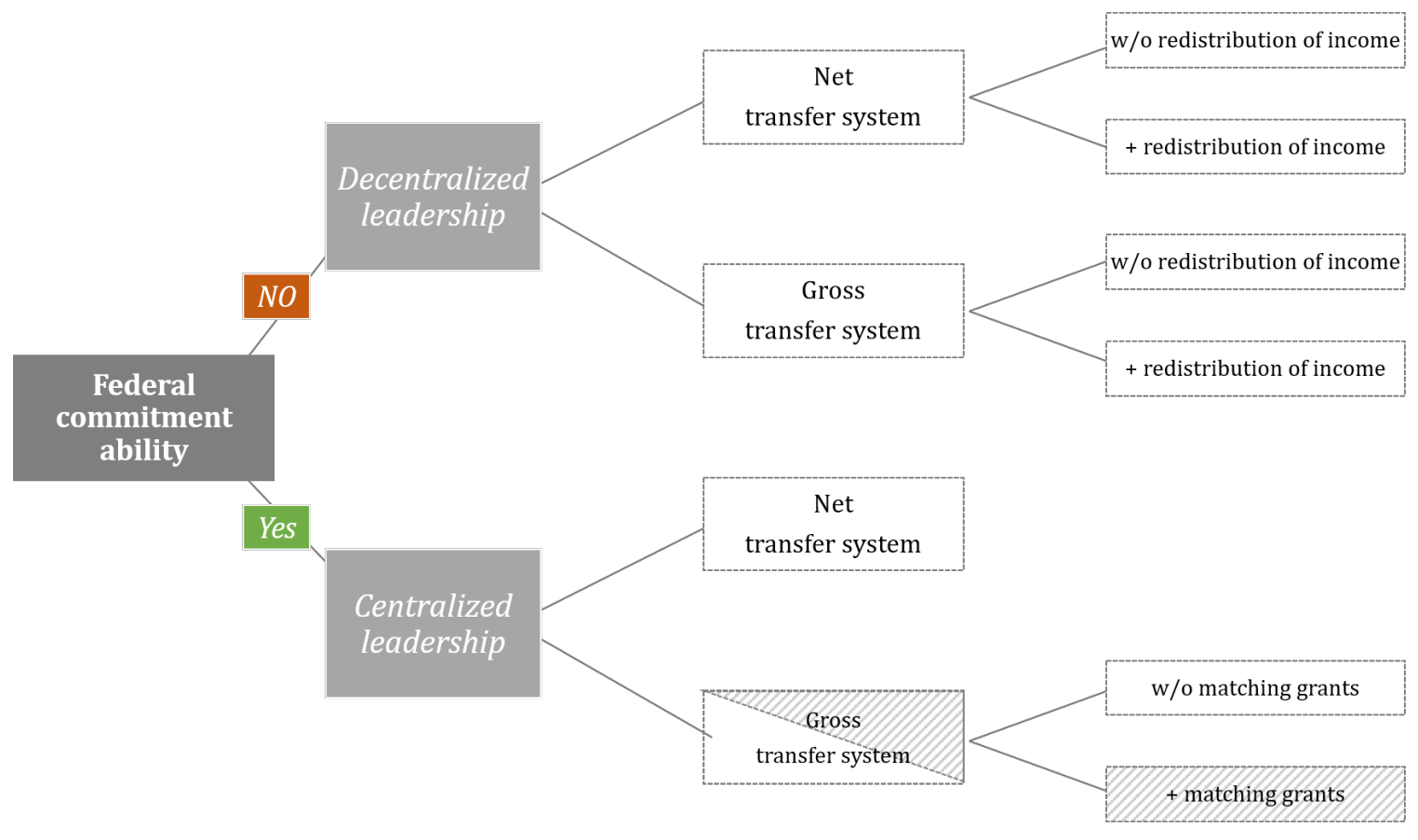

\subsection{Decentralized leadership}

If regional governments are allowed (or required) to define their policies first and are able to fully commit to them, then they are policy leaders in a formal sense. Alternatively, regional governments can also be de facto policy leaders if the federal government defines policy first, but is unable to commit and thus adjusts its policy after observing the outcome of regional policy choices. This is often discussed in the context of the federal government "bailing out" regions despite having promised not to do so (Wildasin, 1999, Akai and Sato, 2008). If regions anticipate that they have a "soft" budget constraint, they incorporate the federal government's response when setting the policy that maximizes their (regional) utilities.

To capture the idea that the federal government responds to regional governments' choices, we model the latter as Stackelberg leaders and the federal government as a Stackelberg follower. In the first stage, regional governments select their taxes in order to finance public goods before the central government decides on transfers in stage two. The game is solved by backward induction and for different types of transfer systems.

\subsubsection{Net single transfer system}

In this first system that we consider, transfers are self-financing, and there is only one type of transfer. In the second stage, the federal government chooses the level of transfers to maximize 
social welfare after observing the regional governments' policy choices (i.e. maximization problem 17). Regions anticipate that transfers are a function of their own tax rates which will be set such that 19 and the federal budget constraint (4) hold. This results in the same first-order conditions as in solving the Nash equilibrium problem (17).

To derive the federal response to a marginal change in region $i$ 's tax rate, we start by differentiating (4):

$$
\frac{\partial s_{i}}{\partial t_{i}}=-\sum_{m \neq i} \frac{\partial s_{m}}{\partial t_{i}}=-(n-1) \frac{\partial s_{j}}{\partial t_{i}}
$$

where the second equality is a consequence of imposing symmetry $(m=j)$.

Differentiating (19) with respect to $t_{i}$ and canceling $\partial^{2} U / \partial G_{i}^{2}=\partial^{2} U / \partial G_{j}^{2}$ due to symmetry yields $\partial G_{i} / \partial t_{i}=\partial G_{j} / \partial t_{i}$. Using (25), the change in public consumption in region $i$ as a reaction to a change in the local tax rate is then given by:

$$
\frac{\partial G_{i}}{\partial t_{i}}=\frac{\partial t_{i} k_{i}}{\partial t_{i}}+\beta(n-1) \frac{\partial t_{j} k_{j}}{\partial t_{i}}+(1-\beta) \frac{\partial s_{i}}{\partial t_{i}}
$$

The first term describes region $i^{\prime} s$ revenue effect when setting the tax $t_{i}$; the second term is the received "spill-back effect" of higher public good provision in other regions due to the inflow of capital; and the third term captures the change in the federal transfer, again adjusted for the degree to which this transfer spills out to other regions. With perfect spillovers $(\beta=1)$, the spill-back effect is complete and no adjustment of the federal transfer is required.

The change in public consumption in region $j$ in response to a change in the tax rate in region $i \neq j$ is given by

$$
\begin{aligned}
\frac{\partial G_{j}}{\partial t_{i}} & =\frac{\partial\left(t_{j} k_{j}+s_{j}\right)}{\partial t_{i}}+\beta \frac{\partial\left(t_{i} k_{i}+s_{i}\right)}{\partial t_{i}}+\beta \sum_{m \neq i, j} \frac{\partial\left(t_{m} k_{m}+s_{m}\right)}{\partial t_{i}} \\
& =(1+\beta(n-2)) \frac{\partial t_{j} k_{j}}{\partial t_{i}}+\beta \frac{\partial t_{i} k_{i}}{\partial t_{i}}-\frac{1-\beta}{n-1} \frac{\partial s_{i}}{\partial t_{i}}
\end{aligned}
$$

where symmetry is applied in the second line. Equating (26) and (27) and simplifying leads to an implicit definition of the best-response function $s_{i}\left(t_{i}, t_{j}\right)$ :

$$
(1-\beta) \frac{\partial s_{i}}{\partial t_{i}}=(1-\beta) \frac{n-1}{n} \frac{\partial t_{j} k_{j}}{\partial t_{i}}-(1-\beta) \frac{n-1}{n} \frac{\partial t_{i} k_{i}}{\partial t_{i}}
$$


or, for $\beta<1$,

$$
\frac{\partial s_{i}}{\partial t_{i}}=\frac{n-1}{n}\left(\frac{\partial t_{j} k_{j}}{\partial t_{i}}-\frac{\partial t_{i} k_{i}}{\partial t_{i}}\right),
$$

which is identical to the function derived by Koethenbuerger (2004) in the absence of spillovers. We now provide some intuition for why this is the case.

The transfer response function consists of two parts. The first term on the right-hand side of 28 is positive and reflects the revenue increase in every other region in response to region $i$ 's tax increase. To maximize welfare (which, under symmetry, implies equalizing public consumption across regions), the transfer to region $i$ has to be increased. However, due to the spillovers, region $i$ only needs to receive a (1- $\beta$ )-fraction of this surplus, as $\beta$ spills over even in the absence of federal redistribution. If $\beta$ increases, more of the capital leakage spills back to region $i$, and a smaller federal transfer is required. With perfect spillovers, the entire increase in public good production spills back to $i$, rendering a transfer increase unnecessary.

The second term in (28) represents the local revenue increase in region $i$ due to the tax increase. As $G_{i}=G_{j}$ will hold in the equilibrium, region $i$ will only keep the part $1 / n$ of this revenue increase, whereas it has to surrender the remaining $(n-1) / n$ in the form of a decreased federal transfer. However, due to the spillovers, region $i$ already loses some of its revenue increase, such that the reduction of the transfer only needs to be a (1- $\beta$ )-fraction of it. With $\beta=1$, there is no need to reduce region $i$ 's transfer as all other regions equally share the benefits of the revenue increase.

Because not only public production, but also the transfer itself spills across regions (in the form of public consumption), region $i$ 's transfer has to be adjusted accordingly. For example, with $\beta=0.5$, the transfer change to region $i$ has to be twice as high in order to achieve the desired outcome. This is the reason why the spillover parameter cancels out in (29). Last, note that with perfect spillovers, both sides of (28) are zero, indicating that any pattern of federal transfers leads to the same outcome as all regions consume the (pure) public good equally irrespective of where it is produced ${ }^{22}$

In stage 1, regional governments maximize the utility of their residents. When setting the optimal tax rate, they consider its effect on the choices made by the representative firm and

\footnotetext{
${ }^{22}$ If spillovers were asymmetric in the sense that $\beta_{i j} \neq \beta_{j i}$ and/or $\beta_{i j} \neq \beta_{i m}$, for $i \neq j, i \neq m$, the spillover parameters would not cancel. In this case, the best-response function would depend on the region in question, and on the associated vector of spillover parameters.
} 
household in the region, as well as on the federal transfer:

$$
\max _{t_{i}} U\left(\left[f\left(k_{i}\right)-f^{\prime}\left(k_{i}\right) k_{i}+\bar{k}_{i} R\right],\left[\left[t_{i} k_{i}+s_{i}\left(t_{i}, t_{m}\right)\right]+\beta \sum_{\substack{m=1 \\ m \neq i}}^{n}\left[t_{m} k_{m}+s_{m}\left(t_{i}, t_{m}\right)\right]\right]\right) .
$$

The first-order conditions and the resulting optimality conditions are derived in the Appendix A.2.1. We combine our results in the following proposition:

Proposition 1 Decentralized leadership with single net transfer system for public production. The decentralized equilibrium under decentralized leadership, with symmetric regions and transfer system (4) is characterized by:

$$
M R S^{D E}=\frac{n}{1+\beta(n-1)}=n \cdot M R S^{P O}
$$

Proof: See Appendix A.2.1.

The $M R S^{D E}$ exceeds the first-best $M R S^{P O}$ for $n>1$, such that the tax is set too low. Under decentralized leadership, the federal transfer corrects for the distortions of capital outflow triggered by capital tax competition and free-riding on the public goods of other regions, as can be seen in (28). The distortion in the tax rate is introduced via the revenue-sharing transfer system and the inability of the federal government to commit (i.e., it "bails out" regions by ensuring equal public consumption everywhere). Expression (31) corresponds to the solution in Koethenbuerger (2004), corrected for the presence of spillovers. If spillovers are perfect $(\beta=1)$, the equilibrium collapses to the case of a federal public good and pure free-riding on transfers first derived by Warr (1983).

Using the utility function defined by (15), we can solve (31) for the resulting tax rate in a symmetric decentralized equilibrium:

$$
t^{D E}=\frac{c}{k n}=\frac{t^{P O}}{n}
$$

Intuitively, regional governments anticipate that the federal government will set transfers to maximize utilities which leads to equalized public consumption in symmetry. They know that they can only keep an $n$-fraction of the additional revenue from a tax increase, which results in an under-provision of the public good. Importantly, this under-provision is unrelated to fiscal 
and environmental spillovers (which are internalized by the transfer), but is entirely due to the tax-transfer system by the federal government.

\subsubsection{Net transfer system with additional redistribution of income}

In this subsection, we assume that the federal government has access not only to a transfer that equalizes public consumption, but to an additional transfer targeting private consumption, as defined by (5). Solving the federal government's problem in stage 2 leads to (see Appendix A.2.2):

$$
\begin{array}{lll}
U^{\prime}\left(G_{i}\right)=U^{\prime}\left(G_{j}\right) & \Rightarrow G_{i}=G_{j} & \forall i, j, \\
U^{\prime}\left(c_{i}\right)=U^{\prime}\left(c_{j}\right) & \Rightarrow c_{i}=c_{j} & \forall i, j .
\end{array}
$$

The federal government chooses the two types of transfers such that the marginal utilites of private and public consumption across regions are equalized. If regions are identical, this implies equal private and public good consumption across regions. Together with the budget constraints, this defines the federal policy program and consequently the reaction functions $s_{i}\left(t_{i}, t_{j}\right)$ and $\tau\left(t_{i}, t_{j}\right)$.

The reaction function of $s_{i}$ is identical to the case without income distribution and is given by (29), as public consumption is once again equalized according to (33). The reaction function of the private consumption transfer is (derivation in Appendix A.2.2):

$$
\frac{\partial \tau_{i}}{\partial t_{i}}=\frac{n-1}{n} k>0 \quad \text { and } \quad \frac{\partial \tau_{j}}{\partial t_{i}}=-\frac{1}{n} k<0
$$

Without a transfer, the marginal reduction of private income due to an increase in the tax in region $i$ would be given by $k$. Due to the transfer, region $i$ receives $\frac{n-1}{n} k$ and all regions $j$ have to pay $\frac{1}{n} k$. Thus, the cost of substituting private with public consumption in a particular region is shared evenly across all regions.

The decentralized equilibrium with additional redistribution of income is characterized by Proposition 2.

Proposition 2 Decentralized leadership with an additional net income transfer system.

The symmetric equilibrium with spillovers under decentralized leadership, in which the federal 
government uses a net transfer system for public as well as private consumption, is Paretooptimal:

$$
M R S^{D E_{I}}=\frac{1}{1+(n-1) \beta}=M R S^{P O}
$$

\section{Proof: See Appendix A.2.2.}

This means that the result by Silva (2016) for strictly local public goods also applies in the presence of spillovers. Regional governments anticipate that the federal government equalizes both public and private consumption, inclusive of any spillover effects, and set optimal tax rates ${ }^{23}$ If the federal government can redistribute private income, in addition to public consumption, the distortion from the revenue sharing system is removed.

\subsubsection{Gross transfer system(s)}

In comparison to the net transfer system, the ex post transfers in a gross transfer scheme are financed by an additional federal tax. To abstract from issues related to vertical tax competition (see, e.g., Dahlby and Wilson, 1994; Keen and Kotsogiannis, 2002), we assume this additional tax to be a non-distortive head tax ${ }^{24}$ We start by assuming that the federal budget constraint is given by $\sum_{i=1}^{n} s_{i}=n T$, before extending the results to an individualized federal tax $T_{i}$ and an additional redistribution of income as in (5).

The federal government chooses the lump-sum tax (and hence the aggregated amount of the transfer) and the distribution of transfers between the region. Solving the problem leads to (see Appendix A.2.3):

$$
\begin{aligned}
& U^{\prime}\left(G_{i}\right)=U^{\prime}\left(G_{j}\right) \Rightarrow \quad G_{i}=G_{j} \quad \forall i, j \\
& \frac{\partial U}{\partial G_{i}}=\frac{1}{\frac{\partial U}{\partial c_{i}}}=\frac{1}{1+(n-1) \beta}=M R S_{i}^{P O} \quad \forall i
\end{aligned}
$$

Eq. (37) states that the federal government allocates transfers to equalize the marginal utilities of public goods (again, with identical regions, this translates to the same level of public

\footnotetext{
${ }^{23}$ With a self-financing transfer system and symmetry, it must be that $s_{i}=0 \forall i$ in equilibrium. In order to supply the efficient amount of the public good, the regions have to set the tax rate to $t^{P O}$.

${ }^{24}$ Given that all federal inputs are fixed in this model, this could be substituted by a federal tax on capital or labor without loss of generality.
} 
consumption everywhere). Eq. (38) implies that adding a lump-sum tax provides the federal governments with an additional policy instrument to achieve the efficiency condition of private and local public good consumption, i.e., it ensures an optimal amount of public consumption in each region. Due to symmetry, private consumption will be equalized as well.

To derive the best-response functions of the federal policy to a change in regional tax rates, we differentiate the first-order conditions of the symmetric equilibrium with respect to $t_{i}$. Furthermore, from the federal budget constraint, it follows that

$$
\frac{\partial s_{i}}{\partial t_{i}}=n \frac{\partial T}{\partial t_{i}}-(n-1) \frac{\partial s_{j}}{\partial t_{i}}
$$

If region $i$ changes the tax $t_{i}$, then this will be compensated by a change in the lump-sum $\operatorname{tax} T$ that is financed by all $n$ regions, plus a change in transfers for all other $n-1$ regions. For $\beta<1{ }^{25}$ this leads to (see Appendix A.2.3):

$$
\frac{\partial s_{i}}{\partial t_{i}}=\frac{\partial T}{\partial t_{i}}-\frac{n-1}{n}\left(\frac{\partial t_{i} k_{i}}{\partial t_{i}}-\frac{\partial t_{j} k_{j}}{\partial t_{i}}\right) \quad \text { and } \quad \frac{\partial s_{j}}{\partial t_{i}}=\frac{\partial T}{\partial t_{i}}+\frac{1}{n}\left(\frac{\partial t_{i} k_{i}}{\partial t_{i}}-\frac{\partial t_{j} k_{j}}{\partial t_{i}}\right)
$$

The second term of the reaction function is equivalent to that in the net transfer system (29). This means that the federal government corrects for the distortions due to capital outflow and free-riding on public goods, and that regions equally share the result of any local revenue change. The difference to the net transfer system consists in the change in the federal tax $T$ due to a change in $t_{i}$.

The equilibrium with a gross transfer system is characterized by Proposition 3.

Proposition 3 Decentralized equilibrium with a gross transfer system.

The symmetric equilibrium under decentralized leadership with spillovers, in which the federal government uses a gross transfer system, is entirely financed by federal transfers and given by

$$
\begin{aligned}
& M R S^{D E_{g}}=M R S^{P O} \\
& \text { with } t_{i}=0 \forall i
\end{aligned}
$$

Proof: The first line of (40) is simply a restatement of (38). In a symmetric equilibrium,

\footnotetext{
${ }^{25}$ For $\beta=1$, both sides of the reaction functions are zero, and again, as with a net transfer system 4.1.1, any federal transfer will lead to the same outcome since all regions consume the "pure" public good.
} 
the federal government can achieve the social optimum by equalizing (the marginal utility of) public consumption across regions and choosing an appropriate gross transfer $T$ to achieve the desired mix of public and private consumption ${ }^{26}$ For the second part, consider the optimality condition of the regional governments in stage 1 (the maximization problem is described in Appendix A.2.3):

$$
\frac{\partial U}{\partial t_{i}}=\frac{\partial U}{\partial c_{i}} \frac{\partial c_{i}}{\partial t_{i}}+\frac{\partial U}{\partial G_{i}} \frac{\partial G_{i}}{\partial t_{i}} \leq 0 ; \quad t_{i} \geq 0 ; \quad \frac{\partial U}{\partial t_{i}} \cdot t_{i}=0
$$

For $t_{i}=0$, the first-order condition will generally not be equal to zero.

The effect of a marginal change in region $i$ 's tax rate on public consumption, including the reaction of the federal transfers, is given by

$$
\begin{aligned}
\frac{\partial G_{i}}{\partial t_{i}} & =\frac{\partial t_{i} k_{i}}{\partial t_{i}}+\frac{\partial s_{i}}{\partial t_{i}}+\beta(n-1)\left(\frac{\partial t_{j} k_{j}}{\partial t_{i}}+\frac{\partial s_{j}}{\partial t_{i}}\right) \\
& =[1+\beta(n-1)]\left(\frac{\partial T}{\partial t_{i}}+\frac{1}{n}\left(\frac{\partial t_{i} k_{i}}{\partial t_{i}}+(n-1) \frac{\partial t_{j} k_{j}}{\partial t_{i}}\right)\right)
\end{aligned}
$$

where the second line follows from substituting (39).

Because conditions (37)- (38) hold, it must be that $\partial G_{i} / \partial t_{i}=0$. Because the (efficient and symmetric) outcome is given, the level of public consumption in each region cannot be influenced by regions' choice of the tax rate, as higher regional tax revenue will simply be equalized by a reduction in the transfer. This implies that the federal government's adjustment of $\frac{\partial T}{\partial t_{i}}$ is such that the term in parenthesis is zero:

$$
\frac{\partial T}{\partial t_{i}}=-\frac{1}{n}\left(\frac{\partial t_{i} k_{i}}{\partial t_{i}}+(n-1) \frac{\partial t_{j} k_{j}}{\partial t_{i}}\right)=-\frac{k}{n}
$$

where the last equality follows from substituting 10 .

The marginal change in private consumption in region $i$ in response to a unilateral marginal

\footnotetext{
${ }^{26}$ Conversely, we can state that with ex-ante identical regions, any non-symmetric outcome will not be efficient as the federal government can only tailor $s_{i}$ to individual regions, but not $T$. This means that the MRS cannot be equalized across regions if regional tax rates differ. However, non-symmetric tax rates by ex-ante identical regions will not constitute a Nash equilibrium in the first stage of the game and thus can be ruled out.
} 
increase of the regional tax rate is given by

$$
\begin{aligned}
\frac{\partial c_{i}}{\partial t_{i}} & =-f^{\prime \prime}\left(k_{i}\right) \frac{\partial k_{i}}{\partial t_{i}} k_{i}+\frac{\partial R}{\partial t_{i}} \bar{k}_{i}+\frac{k}{n} \\
& =-k \cdot \frac{n-1}{n}<0 .
\end{aligned}
$$

This implies that $\frac{\partial U_{i}}{\partial t_{i}}<0$, such that all regions would have an incentive to choose lower capital tax rates. In other words, $t_{i}>0 \forall i$ cannot be a subgame-perfect equilibrium in the first stage of the game, because regions would have an incentive to unilaterally reduce the tax rate. Hence it follows that the only symmetric equilibrium tax rate is $t_{i}=0 \forall i$.

Proposition 3 describes the case where the regional transfers are financed by a federal tax that is uniform across regions, and without an additional region-specific income transfer. The following corollary relaxes these assumptions, building on Propositions 2 and 3 :

Corollary 1 Extensions to the gross transfer system.

The symmetric equilibrium with a federal gross transfer system that

(i) finances transfers using individualized head taxes $\left(\sum_{i=1}^{n} s_{i}=\sum_{i=1}^{n} T_{i}\right)$ or

(ii) uses additionally redistribution of income $\left(\sum_{i=1}^{n} s_{i}=n T\right.$ combined with $\left.\sum_{i=1}^{n} \tau_{i}=0\right)$

is Pareto-optimal. In both systems, the regional governments lose their fiscal power in the sense that the equilibrium is independent of regional tax rates.

Proof: A gross transfer system financed by individual taxes (part $i$ ) is similar to a net transfer system with additional redistribution of income as discussed in Proposition 2. The only difference is that the budget constraints (4) and (5) do not individually have to be zero, but their sum. This means that this is a relaxation of the situation described in section 4.1.2, and therefore it has to result in an efficient outcome as well. Similarly, adding an additional income transfer to a gross transfer system (part $i i$ ) is redundant with ex-ante identical regions, since income redistribution already exists via the uniform federal tax. Therefore, the equilibrium has to be efficient.

In both cases, the marginal utility is equalized across regions not only for public consumption, but also for private consumption as a consequence of the federal government's policy 
setting (with symmetric regions, this translates to public and private consumption being equalized everywhere). This means that regional governments cannot affect the utility in their jurisdiction by changing tax rates. Intuitively, if the government of region $i$ were to increase its tax rate on capital, the transfers $s_{i}$ and/or $\tau_{i}$ would simply be adjusted downward, leaving public and private consumption unchanged everywhere. Regional tax rates can therefore take any value, unlike the case described in Proposition 3. For a more formal proof, see Appendix A.2.3.

\subsection{Centralized leadership}

We now turn to the case in which the federal government is able to commit to its policy choices, regardless of regions' decisions, and the latter know this. The roles are thus reversed: We model the federal government as the Stackelberg leader and the regional governments as followers that set their policy in the second stage conditional on the federal policy. In the first stage, the federal government anticipates the response by the regional governments.

Unlike in the Nash equilibrium and in the decentralized leadership model, the form of the transfer matters when the central government is the policy leader. In particular, the federal government can either pay a lump-sum grant or a matching grant that is proportional to regions' public production ${ }^{27}$ In many federations, the transfer system has some degree of conditionality as a device for federal influence over regional programs (Boadway and Tremblay, 2012).

A matching grant necessarily requires a gross transfer system, since public production will be strictly positive, and the sum of payments thus cannot be zero. Therefore, a net transfer system has to be based on lump-sum transfers (in the sense that they do not depend on $\left.g_{i}\right)$. Whether the transfers aim at public or private consumption is immaterial: All lump-sum transfers will drop out of regions' first-order conditions and thus the equilibrium under a net transfer system and centralized leadership is the same as in the Nash setting discussed in section 3.2. The equilibrium is inefficient and characterized by (21), and under symmetry we have that $s_{i}=T=0 \forall i$.

In the following, we analyze the equilibrium if the federal government has access to a

\footnotetext{
${ }^{27}$ For simplicity, we have modeled the grant as a lump-sum transfer above. In the Nash equilibrium, regional governments take the money amount of the transfer as given, regardless of how this amount is determined. In the decentralized leadership setting, the grant is chosen such that public consumption is equalized across regions $\left(G_{i}=G_{j}\right)$. Again, the form of the grant is immaterial.
} 
matching grant of the form

$$
s_{i}^{M G} \equiv \alpha \cdot g_{i} \quad \forall i
$$

with $\alpha>0$, which requires a separate source of revenue for the federal government. We specify this source as a uniform head tax $T{ }^{28}$ The entire revenue from this lump-sum tax is exhausted by the transfer system:

$$
n \cdot T=\alpha \cdot \sum_{i=1}^{n} g_{i}
$$

The timing of the centralized-leadership-game is as follows: In the first stage, the federal government chooses a matching rate $\alpha$. Because the federal government anticipates the reaction of the regional governments, setting $\alpha$ defines $T$ through 46 . In the second stage, regional governments choose capital taxes $t_{i}$ to maximize the utility of their resident households while treating the matching rate as given.

We collect our results in the following proposition:

\section{Proposition 4 Centralized leadership}

(i) If the federal government uses a lump-sum transfer, which is necessarily the case in a net transfer system, the centralized outcome is characterized by the Nash equilibrium.

(ii) If the federal government has access to a matching grant that is financed via a federal lump-sum tax, Pareto-efficiency can be induced by choosing the following matching rate:

$$
\alpha^{C E}=\frac{(n-1) \beta+(1-\beta) \epsilon}{1+(n-1) \beta} .
$$

with $\epsilon$ representing the (absolute) elasticity of regional capital demand w.r.t. the tax rate.

(iii) If $n>1$ and $\epsilon<\frac{n-1}{n}$, an increase in spillovers increases the matching rate, and vice versa.

Proof: See Appendix A.3.

\footnotetext{
${ }^{28}$ Ogawa (2006) uses a region-specific tax $T_{i}$, but one that is not self-financing and therefore does not correspond to the income-redistributing net transfer considered above (note that he does not discuss the issue of commitment). The result is the same under symmetry, as all regions pay the same tax, but the outcome would differ with asymmetric regions. Since both the population and the total amount of capital is held fixed, $T$ could also be specified as a tax on labor, or as a residence-based tax on capital $\bar{k}_{i}$.
} 
Expression (47) is equivalent to the result derived by Ogawa (2006) based on a matching grant that is financed by region-specific lump-sum taxes (as opposed to the uniform federal head tax considered here). The federal government sets the optimal matching rate $\alpha$ such that the fiscal externality induced by capital tax competition and the technical externality due to spillovers are both exactly internalized. The matching rate depends on the number of regions, the elasticity of a region's capital demand with respect to the tax rate, and the strength of the spillover effect.

To gain some intuition, we start with the case of no spillovers. With $\beta=0$, the matching rate corrects for the fiscal externality from tax competition only (as there is nothing else to correct): $\left.\alpha^{C E}\right|_{\beta=0}=\epsilon=-\frac{\partial k_{i}}{\partial t_{i}} \frac{t}{k}=(n-1) \frac{\partial k_{j}}{\partial t_{i}} \frac{t}{k}$. The matching rate equals the marginal change in tax revenue in all other regions (proportional to the employed capital) due to a marginal increase in the tax in region $i$. This is the fiscal externality that local governments would not consider in the absence of a federal matching rate, and which is the cause for the inefficiency from capital tax competition (see, e.g. Wilson, 1999).

In the presence of spillovers, there is an additional reason to subsidize local public production (the first part in the numerator of (47)), as regions do not consider the benefits of $g_{i}$ accruing in regions $j \neq i$. This effect increases in the number of regions. However, a $\beta$-fraction of the capital outflow spills back to region $i$ in the form of higher public good provision in the other regions (the second part in the denominator of (47)), such that spillovers reduce the fiscal distortion. In other words, two things happen when $\beta$ increases: First, the technical externality due to free-riding increases (which requires a higher $\alpha^{C E}$ ), and second, the fiscal externality is mitigated (which reduces the optimal matching rate). The net effect depends on the relative importance of the technical and fiscal externalities. Part (iii) of Proposition 4 states that if the elasticity of capital demand is not too large $\left(\epsilon<\frac{n-1}{n}\right)$, the second effect dominates, such that the optimal matching rate decreases in $\beta$, and vice versa for large $\epsilon$.

Note, finally, that providing the federal government with a matching grant makes no difference in the absence of commitment (decentralized leadership), as the regions anticipate the total transfer $s_{i}$ that will result in $G_{i}=G_{j}$, regardless of its composition. 


\subsection{Discussion}

Figure 2 provides and overview of our results. We find that the social optimum can be achieved with and without federal commitment, depending on the available policy instruments.

Figure 2: Overview of models and results

\begin{tabular}{|c|c|c|}
\hline $\begin{array}{l}\text { Federal } \\
\text { transfer system }\end{array}$ & $\begin{array}{l}\text { Decentralized leadership } \\
\text { Federal non-commitment }\end{array}$ & $\begin{array}{l}\text { Centralized leadership } \\
\text { Federal commitment }\end{array}$ \\
\hline $\begin{array}{r}\text { Net transfer system: } \\
\qquad \sum_{i=1}^{n} s_{i}=0\end{array}$ & $M R S^{D E}=\frac{n}{1+\beta(n-1)}=n M R S^{P O}$ & Nash setting \\
\hline $\begin{array}{l}\text { + private income redistribution: } \\
\sum_{i=1}^{n} s_{i}=0 \text { and } \sum_{i=1}^{n} \tau_{i}=0\end{array}$ & $M R S^{D E_{t}}=\frac{1}{1+\beta(n-1)}=M R S^{P O}$ & Nash setting \\
\hline $\begin{array}{l}\text { Gross transfer system: } \\
\qquad \sum_{i=1}^{n} s_{i}=n T\end{array}$ & $M R S^{D E_{g}}=\frac{1}{1+\beta(n-1)}=M R S^{P O}$ & Nash setting \\
\hline $\begin{array}{l}\text { + private income redistribution: } \\
\sum_{i=1}^{n} s_{i}=n T \text { and } \sum_{i=1}^{n} \tau_{i}=0\end{array}$ & $M R S^{D E_{g}}=\frac{1}{1+\beta(n-1)}=M R S^{P O}$ & Nash setting \\
\hline $\begin{array}{l}\text { + matching grant: } \\
\sum_{i=1}^{n} s_{i}=n T \text { with } s_{i}=\alpha g_{i}\end{array}$ & $\begin{array}{l}\text { Same result as gross transfer system without } \\
\text { matching grant (due to non-commitment) }\end{array}$ & $M R S^{C E_{g}}=\frac{1}{1+\beta(n-1)}=M R S^{P O}$ \\
\hline
\end{tabular}

If the federal government cannot commit, then the result is inefficient under a single net transfer system. Efficiency can be obtained if there are two types of self-financing transfers: One for public consumption, and a separate transfer for the numeraire consumption good. These two results are qualitatively similar to previous results derived for the special case of strictly local public goods by Koethenbuerger (2004) and Silva (2016). Intuitively, the transfer depends on equilibrium public consumption in each region, and thus fully incorporates not only the presence of capital outflow but also of spillovers. The presence of spillovers changes the equilibrium tax rate, but the qualitative nature of the results are the same as in the case of publicly provided private goods.

If the federal government uses a gross transfer system such that region-specific transfers 
are financed by a uniform federal tax, the outcome is efficient, but financed entirely by federal transfers. Regional government do not have an incentive to set $t_{i}>0$ as they anticipate that they are "bailed out" by the federal government setting transfers $s_{i}$ and the $\operatorname{tax} T$ such that efficiency is reached. A gross transfer system with an individualized federal tax $T_{i}$ (or with additional redistribution of income) is efficient as well, but such a system renders the regions powerless in the sense that the equilibrium outcome is independent of regions' tax rates.

If the federal government is able to commit to its policy choices, the equilibrium coincides with the (inefficient) Nash equilibrium unless the government has access to matching grants. These grants have to be financed via some other source of revenue and therefore cannot be revenue neutral. The effect of the spillover parameter on the optimal matching rate depends on the elasticity of capital demand with respect to the tax rate. If the demand for regional capital is elastic, the detrimental effects of capital tax competition dominate the efficiency loss. Since spillovers cause a part of the capital outflow to spill back into the region of origin, they mitigate the inefficiency from decentralization and thus lead to a decrease in the optimal matching rate. In contrast, if regional capital is not very responsive to regional tax rate differentials, then an increase in spillovers increases regions' incentives to free-ride. To counteract this, the federal government has to increase the matching rate.

\section{Concluding remarks}

We develop a model of capital taxation within a federation, in which the regionally provided public goods are allowed to spill across regions. We ask two questions: (i) To what extent does the presence of spillovers affect the inefficiency associated with decentralized decision-making, and (ii) how does this depend on the ability of the federal government to commit to a policy as well as on the available policy instruments? Our paper synthesizes the literature on capital tax competition in the presence of spatial externalities by reproducing the previous results as special cases (i.e., in the absence of spillovers), and generates new results within the same framework.

Because the federal government cares about the welfare of all households within the federation, it may not be able to commit to its policy but instead ends up bailing out regions. Whether this leads to an inefficient outcome depends on the available policy instruments. Sim- 
ilarly, the outcome can be efficient or inefficient if the federal government can commit. In this sense, commitment is neither a necessary nor a sufficient condition for efficiency, or lack thereof, in the context of decentralized public production. This contrasts with the implications of the literature on soft budget constraints, which has argued that (i) federal commitment is required for efficiency but (ii) is likely to be absent.

Throughout this paper, we assume that regions are symmetric, which is a routine assumption in the literature. This allows us to generate closed-form results, but it naturally is a poor description of reality, where large and small regions compete with each other for a mobile tax base. We furthermore abstract from asymmetric information, which is the principal motivation for the decentralized provision of public goods in the first place. If the federal government is benevolent and fully informed, decentralization can only lead to an efficiency loss by construction. Our paper shows how this efficiency loss changes if we allow for spillovers. If the benefits of decentralization also depend on the presence of spillovers, they have to be considered along with the costs when deciding about decentralizing government functions and transfer systems in a federation. We believe this to be a fruitful avenue for future research.

\section{References}

Akai, N. and Sato, M. (2008). Too big or too small? a synthetic view of the commitment problem of interregional transfers. Journal of Urban Economics, 64(3):551-559.

Arzaghi, M. and Henderson, J. V. (2005). Why countries are fiscally decentralizing. Journal of Public Economics, 89(7):1157-1189.

Becker, J. and Runkel, M. (2012). Even small trade costs restore efficiency in tax competition. Journal of Urban Economics, 72(23):191-195.

Bjorvatn, K. and Schjelderup, G. (2002). Tax competition and international public goods. International Tax and Public Finance, 9(2):111-120.

Bloch, F. and Zenginobuz, U. (2007). The effect of spillovers on the provision of local public goods. Review of Economic Design, 11(3):199-216. 
Bloch, F. and Zenginobuz, Ü. (2015). Oates decentralization theorem with imperfect household mobility. International Tax and Public Finance, 22(3):353-375.

Blöchliger, H. and Kim, J. (2016). Fiscal Federalism 2016 Making Decentralisation Work: Making Decentralisation Work. OECD Publishing.

Boadway, R. (2004). The theory and practice of equalization. CESifo Economic Studies, $50(1): 211-254$.

Boadway, R. and Tremblay, J.-F. (2012). Reassessment of the Tiebout model. Journal of Public Economics, 96(1112):1063-1078.

Bondarev, A., Hintermann, B., Krysiak, F., and Winkler, R. (2017). The intricacy of adapting to climate change: Flood protection as a local public goods game. CESifo Working Paper No. 6382 .

Breuille, M.-L., Madies, T., and Taugourdeau, E. (2010). Gross versus net equalization scheme in a federation with decentralized leadership. Journal of Urban Economics, 68(2):205-214.

Brlhart, M., Bucovetsky, S., and Schmidheiny, K. (2015). Chapter 17 - taxes in cities. In Duranton, G., Henderson, J. V., and Strange, W. C., editors, Handbook of Regional and Urban Economics, volume 5 of Handbook of Regional and Urban Economics, pages 1123 1196. Elsevier.

Bucovetsky, S. (1991). Asymmetric tax competition. Journal of Urban Economics, 30(2):167181.

Caplan, A. J., Cornes, R. C., and Silva, E. C. (2000). Pure public goods and income redistribution in a federation with decentralized leadership and imperfect labor mobility. Journal of Public Economics, 77(2):265-284.

Dahlby, B. (1996). Fiscal externalities and the design of intergovernmental grants. International Tax and Public Finance, 3(3):397-412.

Dahlby, B. and Wilson, L. S. (1994). Fiscal capacity, tax effort, and optimal equalization grants. Canadian Journal of Economics, 27(3):657-672. 
DePeter, J. A. and Myers, G. M. (1994). Strategic capital tax competition: A pecuniary externality and a corrective device. Journal of Urban Economics, 36(1):66-78.

Eichner, T. and Runkel, M. (2012). Interjurisdictional spillovers, decentralized policymaking, and the elasticity of capital supply. American Economic Review, 102(5):2349-2357.

Fell, H. and Kaffine, D. T. (2014). Can decentralized planning really achieve first-best in the presence of environmental spillovers? Journal of Environmental Economics and Management, 68(1):46-53.

Fuest, C., Huber, B., and Mintz, J. (2005). Capital mobility and tax competition. Foundations and Trends in Microeconomics, 1(1):1-62.

Goodspeed, T. J. (2002). Bailouts in a federation. International Tax and Public Finance, $9(4): 409-421$.

Hayashi, M. and Boadway, R. (2001). An empirical analysis of intergovernmental tax interaction: The case of business income taxes in Canada. Canadian Journal of Economics, $34(2): 481-503$.

Hoyt, W. H. (1991). Property taxation, Nash equilibrium, and market power. Journal of Urban Economics, 30(1):123 - 131 .

Keen, M. and Konrad, K. A. (2013). The theory of international tax competition and coordination. Handbook of Public Economics, 5:257.

Keen, M. J. and Kotsogiannis, C. (2002). Does federalism lead to excessively high taxes? American Economic Review, 92(1):363-370.

Koethenbuerger, M. (2004). Tax competition in a fiscal union with decentralized leadership. Journal of Urban Economics, 55(3):498-513.

Kornai, J., Maskin, E., and Roland, G. (2003). Understanding the soft budget constraint. Journal of Economic Literature, 41(4):1095-1136.

Kuhlmey, F. and Hintermann, B. (2019). The welfare costs of tiebout sorting with true public goods. International Tax and Public Finance, Online First:1-45. 
Lockwood, B. (1999). Inter-regional insurance. Journal of Public Economics, 72(1):1-37.

Oates, W. E. (1999). An essay on fiscal federalism. Journal of Economic Literature, 37(3):11201149.

Oates, W. E. (2005). Toward a second-generation theory of fiscal federalism. International Tax and Public Finance, 12(4):349-373.

Oates, W. E. and Schwab, R. M. (1988). Economic competition among jurisdictions: Efficiency enhancing or distortion inducing? Journal of Public Economics, 35(3):333-354.

Ogawa, H. (2006). Tax competition, spillovers, and subsidies. The Annals of Regional Science, 40(4):849-858.

Ogawa, H. and Wildasin, D. E. (2009). Think locally, act locally: Spillovers, spillbacks, and efficient decentralized policymaking. American Economic Review, 99(4):1206-17.

Pinto, S. M. (2007). Tax competition in the presence of interjurisdictional externalities: The case of crime prevention. Journal of Regional Science, 47(5):897-913.

Qian, Y. and Roland, G. (1998). Federalism and the soft budget constraint. American Economic Review, 88(5):1143-1162.

Silva, E. C. (2016). Tax competition and federal equalization schemes with decentralized leadership. International Tax and Public Finance, 24(1):1-15.

Silva, E. C. and Caplan, A. J. (1997). Transboundary pollution control in federal systems. Journal of Environmental Economics and Management, 34(2):173-186.

Voigt, S. and Blume, L. (2012). The economic effects of federalism and decentralizationa crosscountry assessment. Public Choice, 151(1-2):229-254.

Warr, P. G. (1983). The private provision of a public good is independent of the distribution of income. Economics Letters, 13(2):207-211.

Wellisch, D. (1994). Interregional spillovers in the presence of perfect and imperfect household mobility. Journal of Public Economics, 55(2):167-184. 
Wildasin, D. (1989). Interjurisdictional capital mobility: Fiscal externality and a corrective subsidy. Journal of Urban Economics, 5(2):193-212.

Wildasin, D. E. (1988). Nash equilibria in models of fiscal competition. Journal of Public Economics, 35(2):229-240.

Wildasin, D. E. (1999). Externalities and Bailouts: Hard and Soft Budget Constraints in Intergovernmental Fiscal Relations. The World Bank.

Williams, A. (1966). The optimal provision of public goods in a system of local government. Journal of Political Economy, 74(1):18-33.

Wilson, J. D. (1985). Optimal property taxation in the presence of interregional capital mobility. Journal of Urban Economics, 18(1):73-89.

Wilson, J. D. (1986). A theory of interregional tax competition. Journal of Urban Economics, $19(3): 296-315$.

Wilson, J. D. (1987). Trade, capital mobility, and tax competition. Journal of Political Economy, 95(4):835-856.

Wilson, J. D. (1999). Theories of tax competition. National Tax Journal, 52(2):269-304.

Wilson, J. D. and Wildasin, D. E. (2004). Capital tax competition: Bane or boon? Journal of Public Economics, 88(6):1065-1091.

Zodrow, G. R. and Mieszkowski, P. (1986). Pigou, tiebout, property taxation, and the underprovision of local public goods. Journal of Urban Economics, 19(3):356-370. 


\section{A Appendix}

\section{A.1 Benchmark cases}

The solution to the maximization problem (13) can be found by substituting the definition for $G_{i}$ into the utility function and form the Lagrangian:

$\max _{\left\{c_{1 \ldots n}\right\},\left\{g_{1 \ldots n}\right\}} L=U_{i}\left(c_{i}, g_{i}+\beta \sum_{\substack{m=1 \\ m \neq i}}^{n} g_{m}\right)+\sum_{\substack{j=1 \\ j \neq i}}^{n} U_{j}\left(c_{j}, g_{j}+\beta \sum_{\substack{m=1 \\ m \neq j}}^{n} g_{m}\right)-\lambda \sum_{i=1}^{n}\left(f\left(k_{i}\right)-c_{i}-g_{i}\right)$.

Taking the derivatives w.r.t. to $c_{i}$ and $g_{i}$ (which produces $2 n$ first-order conditions) and rearranging them leads to the following $n$ optimality conditions:

$$
\frac{\partial U_{i}}{\partial c_{i}}=\frac{\partial U_{i}}{\partial G_{i}} \frac{\partial G_{i}}{\partial g_{i}}+\sum_{\substack{j=1 \\ j \neq i}}^{n} \frac{\partial U_{j}}{\partial G_{j}} \frac{\partial G_{j}}{\partial g_{i}} \quad \forall i
$$

At the optimum, the change in the marginal utility of private consumption has to equal the change in the marginal utility of public good consumption for each region. Imposing symmetry, defining the marginal rate of substitution between public and private consumption as $M R S_{i} \equiv \frac{\partial U_{i}}{\partial G_{i}} / \frac{\partial U_{i}}{\partial c_{i}}$ and suppressing the subscript yields expression (14). Finally, substituting $\partial U / \partial c=1 / c$ and $\partial U / \partial G=1 / G$ and equating with (14) leads to the optimal tax given by (16).

The Nash equilibrium is derived by rearranging the first-order condition from (20) to:

$$
M R S_{i} \equiv \frac{\frac{\partial U}{\partial G_{i}}}{\frac{\partial U}{\partial c_{i}}}=-\frac{\frac{\partial c_{i}}{\partial t_{i}}}{\frac{\partial G_{i}}{\partial t_{i}}}
$$

The marginal effect of taxes on consumption (income) is:

$$
\frac{\partial c_{i}}{\partial t_{i}}=-f^{\prime \prime}\left(k_{i}\right) \frac{\partial k_{i}}{\partial t_{i}} k_{i}+\frac{\partial R}{\partial t_{i}} \bar{k}_{i}
$$

The effect on income is separated into the effect on wage income (first term) and capital income (second term), both of which are negative. Increasing taxes increases public consumption at the cost of private consumption. The derivative of public good consumption with respect to 
the tax rate is given by:

$$
\frac{\partial G_{i}}{\partial t_{i}}=k_{i}+t_{i} \frac{\partial k_{i}}{\partial t_{i}}+\beta \sum_{\substack{j=1 \\ j \neq i}}^{n} \frac{\partial t_{j} k_{j}}{\partial t_{i}}
$$

The first term is the mechanical increase in tax revenue if the tax rate is marginally raised, holding capital fixed. The second term is negative and captures the outflow of capital to other regions in response to a marginal tax increase in region $i$. This negative cost is however dampened by positive spillovers from other regions (third term). Substituting (A.3) and A.4 into $\mathrm{A} .2 \mathrm{yields:}$

$$
M R S_{i}^{N E}=\frac{f^{\prime \prime}\left(k_{i}\right) \frac{\partial k_{i}}{\partial t_{i}} k_{i}-\frac{\partial R}{\partial t_{i}} \bar{k}_{i}}{k_{i}+\frac{\partial k_{i}}{\partial t_{i}} t_{i}+\beta \sum_{\substack{j=1 \\ j \neq i}}^{n} \frac{\partial k_{j}}{\partial t_{i}} t_{j}} .
$$

Imposing symmetry and using the capital market clearing conditions $(10)$, we obtain the MRS which defines the Nash equilibrium in (21).

\section{A.2 Decentralized leadership}

\section{A.2.1 Net single transfer system: Proof of Proposition 1}

The optimality condition from solving (30) is given by:

$$
\frac{\partial U_{i}}{\partial G_{i}} \frac{\partial G_{i}}{\partial t_{i}}=-\frac{\partial U_{i}}{\partial c_{i}} \frac{\partial c_{i}}{\partial t_{i}}
$$

The marginal change in private consumption is

$$
\frac{\partial c_{i}}{\partial t_{i}}=-f^{\prime \prime}\left(k_{i}\right) \frac{\partial k_{i}}{\partial t_{i}} k_{i}+\frac{\partial R}{\partial t_{i}} \bar{k}_{i}=-k
$$

where the last equality follows from substituting (10).

The marginal change in public consumption for region $i$ is

$$
\begin{aligned}
\frac{\partial G_{i}}{\partial t_{i}} & =\frac{\partial t_{i} k_{i}}{\partial t_{i}}+\frac{\partial s_{i}}{\partial t_{i}}+\beta(n-1)\left(\frac{\partial t_{m} k_{m}}{\partial t_{i}}+\frac{\partial s_{m}}{\partial t_{i}}\right) \\
& =\frac{\partial t_{i} k_{i}}{\partial t_{i}}+\beta(n-1) \frac{\partial t_{m} k_{m}}{\partial t_{i}}+(1-\beta)\left(\frac{n-1}{n}\right)\left(\frac{\partial t_{m} k_{m}}{\partial t_{i}}-\frac{\partial t_{i} k_{i}}{\partial t_{i}}\right) \\
& =\frac{1+\beta(n-1)}{n}\left(\frac{\partial t_{i} k_{i}}{\partial t_{i}}+(n-1) \frac{\partial t_{m} k_{m}}{\partial t_{i}}\right) \\
& =\frac{1+(n-1) \beta}{n} k,
\end{aligned}
$$


where we used (29) (second line), collected terms (third line) and substituted the capital market clearing conditions (10) (fourth line). The change in mobile capital in region $i$ and regions $m \neq i$ as a response to the change in $t_{i}$ cancels out in equilibrium due to the federal transfer setting:

$$
\frac{\partial t_{i} k_{i}}{\partial t_{i}}+(n-1) \frac{\partial t_{m} k_{m}}{\partial t_{i}}=k+\frac{n-1}{n} \frac{1}{f^{\prime \prime}(k)} t-\frac{n-1}{n} \frac{1}{f^{\prime \prime}(k)} t=k
$$

What remains is the additional positive tax revenue-effect to region $i$ given by $k$. Expression (31) follows directly from substituting A.8 and A.7 into A.6

\section{A.2.2 Net transfer system including private income redistribution}

In stage 2 , the maximization problem of the federal government is given by:

$$
\begin{array}{ll}
\max _{\left\{G_{1 \ldots n}\right\},\left\{s_{1 \ldots n}\right\},\left\{\tau_{1 \ldots n}\right\},\left\{g_{1 \ldots n}\right\},\left\{c_{1 \ldots n}\right\}} \sum_{i=1}^{n} U_{i}\left(c_{i}, G_{i}\right) \quad \text { s.t. } \quad G_{i}=g_{i}+\beta \sum_{\substack{m=1 \\
m \neq i}}^{n} g_{m} \\
& \sum_{i=1}^{n} s_{i}=0 \\
& \sum_{i=1}^{n} \tau_{i}=0 \\
& g_{i}=t_{i} k_{i}+s_{i} \\
& c_{i}=f\left(k_{i}\right)-\frac{\partial f\left(k_{i}\right)}{\partial k_{i}} k_{i}+\bar{k}_{i} R+\tau_{i} .
\end{array}
$$

Substituting the regional governments' and households' budget constraints, the Lagrangian and the first-order conditions can be written as 


$$
\begin{aligned}
\max _{\left\{s_{1 \ldots n}\right\},\left\{\tau_{1 \ldots n}\right\}} L=\sum_{i=1}^{n} U_{i}\left(f\left(k_{i}\right)-\frac{\partial f\left(k_{i}\right)}{\partial k_{i}} k_{i}+\bar{k}_{i} R+\tau_{i}, t_{i} k_{i}+s_{i}+\beta \sum_{\substack{m=1 \\
m \neq i}}^{n} t_{m} k_{m}+s_{m}\right) \\
\quad+\lambda \sum_{i=1}^{n} s_{i}+\mu \sum_{i=1}^{n} \tau_{i} \\
\frac{\partial L}{\partial s_{i}}=\frac{\partial U}{\partial G_{i}}+\beta \sum_{\substack{m=1 \\
m \neq i}}^{n} \frac{\partial U}{\partial G_{m}}+\lambda=0 \quad \forall i \\
\frac{\partial L}{\partial \tau_{i}}=\frac{\partial U}{\partial c_{i}}+\mu=0 \quad \forall i \\
\frac{\partial L}{\partial \lambda}=\sum_{i=1}^{n} s_{i}=0 \\
\frac{\partial L}{\partial \mu}=\sum_{i=1}^{n} \tau_{i}=0
\end{aligned}
$$

Using (A.11) for regions $i$ and $j \neq i$, combining and imposing symmetry yields (33). Equation (34) is derived in the same manner using A.12 for regions $i$ and $j$. Finally, the reaction function for private consumption transfers can be found using (34) and the federal budget constraint A.14 :

$$
\begin{aligned}
& f\left(k_{i}\right)-\frac{\partial f\left(k_{i}\right)}{\partial k_{i}} k_{i}+\bar{k}_{i} R+\tau_{i}=f\left(k_{j}\right)-\frac{\partial f\left(k_{j}\right)}{\partial k_{j}} k_{j}+\bar{k}_{j} R+\tau_{j} \\
& \tau_{i}=-(n-1) \tau_{j} \quad \text { or } \quad \tau_{j}=-\frac{1}{n-1} \tau_{i} .
\end{aligned}
$$

Using (A.14) and (9) in (A.15) and differentiating with respect to $t_{i}$ yields:

$$
f^{\prime \prime}\left(k_{i}\right) \frac{\partial k_{i}}{\partial t_{i}}\left(\bar{k}_{i}-k_{i}\right)-\bar{k}_{i}+\frac{\partial \tau_{i}}{\partial t_{i}}=f^{\prime \prime}\left(k_{j}\right) \frac{\partial k_{j}}{\partial t_{i}}\left(\bar{k}_{j}-k_{j}\right)-\frac{1}{n-1} \frac{\partial \tau_{i}}{\partial t_{i}}
$$

Substituting (10) and solving for $\frac{\partial \tau_{i}}{\partial t_{i}}$ and using it in A.16) as well yields the reaction function (35).

\section{Proof of Proposition 2:}


In the first stage, regional governments solve:

$$
\begin{array}{r}
\max _{G_{i}, g_{i}, c_{i}, t_{i}} U\left(c_{i}, G_{i}\right) \text { s.t. } \\
G_{i}=g_{i}+\beta \sum_{\substack{m=1 \\
m \neq i}}^{n} g_{m} \\
g_{i}=t_{i} k_{i}+s_{i} \\
c_{i}=f\left(k_{i}\right)-f^{\prime}\left(k_{i}\right) k_{i}+\bar{k}_{i} R-\tau_{i} \\
\text { with } \quad s_{i}=s_{i}\left(t_{i}, t_{j}\right) ; \quad s_{j}=s_{j}\left(t_{i}, t_{j}\right) ; \tau_{i}=\tau_{i}\left(t_{i}, t_{j}\right) .
\end{array}
$$

Solving the model results in the same optimality condition as in the Nash equilibrium, given by A.2. The change in private consumption is given by

$$
\frac{\partial c_{i}}{\partial t_{i}}=-f^{\prime \prime}\left(k_{i}\right) \frac{\partial k_{i}}{\partial t_{i}} k_{i}+\frac{\partial R}{\partial t_{i}} \bar{k}_{i}-\frac{\partial \tau_{i}}{\partial t_{i}}=-\frac{1}{n} k
$$

where the last equality follows from substituting (10) and (35). The change in public consumption with respect to $t_{i}$ is equivalent to A.8. Using (A.17) and A.8) in (A.2) leads to (36).

\section{A.2.3 Gross transfer system(s)}

The federal government chooses both $T$ and the region-specific transfers $s_{i}$ to maximize total welfare. After substituting the budget constraints, the Lagrangian can be written as:

$\max _{\left\{s_{1 \ldots n}\right\}, T} L=\sum_{i=1}^{n} U_{i}\left(f\left(k_{i}\right)-\frac{\partial f\left(k_{i}\right)}{\partial k_{i}} k_{i}+\bar{k}_{i} R-T ; t_{i} k_{i}+s_{i}+\beta \sum_{\substack{m=1 \\ m \neq i}}^{n} t_{m} k_{m}+s_{m}\right)+\lambda\left(\sum_{i=1}^{n} s_{i}-n T\right)$

where $\lambda$ is the Lagrangian multiplier of the federal budget constraint. The first-order conditions are given by:

$$
\begin{aligned}
& \frac{\partial L}{\partial s_{i}}=\frac{\partial U}{\partial G_{i}}+\beta \sum_{\substack{m=1 \\
m \neq i}}^{n} \frac{\partial U}{\partial G_{m}}+\lambda=0 \quad \forall i \\
& \frac{\partial L}{\partial T}=-\sum_{i=1}^{n} \frac{\partial U}{\partial c_{i}}-\lambda n=0 \\
& \frac{\partial L}{\partial \lambda}=\sum_{i=1}^{n} s_{i}-n T=0 .
\end{aligned}
$$


Using A.18) for $i$ and $j \neq i$, combining and imposing symmetry yields (37). Combining A.18) and (A.19) yields (38).

Taking the partial derivative of the first-order conditions with respect to $t_{i}$ (which is a parameter from the point of view of the central government) gives

$$
\begin{aligned}
& (1+\beta(n-1)) U_{G G} \frac{\partial G_{i}}{\partial t_{i}}=0 \quad \forall i \\
& -U_{C C} \frac{\partial c_{i}}{\partial t_{i}}=0 \\
& \frac{\partial s_{i}}{\partial t_{i}}=n \frac{\partial T}{\partial t_{i}}-(n-1) \frac{\partial s_{j}}{\partial t_{i}},
\end{aligned}
$$

where $U_{G G} \equiv \frac{\partial^{2} U}{\partial G_{i}^{2}}$ and $U_{C C} \equiv \frac{\partial^{2} U}{\partial c_{i}^{2}}$. Equation A.21 can be rewritten such that $\frac{\partial G_{i}}{\partial t_{i}}=\frac{\partial G_{j}}{\partial t_{i}}$ (differentiating (37) with respect to $t_{i}$ would be an alternative to derive the same expression):

$$
\begin{aligned}
& \frac{\partial t_{i} k_{i}}{\partial t_{i}}+\frac{\partial s_{i}}{\partial t_{i}}+\beta \sum_{\substack{j=1 \\
j \neq i}}^{n}\left(\frac{\partial t_{j} k_{j}}{\partial t_{i}}+\frac{\partial s_{j}}{\partial t_{i}}\right)=\frac{\partial t_{j} k_{j}}{\partial t_{i}}+\frac{\partial s_{j}}{\partial t_{i}}+\beta\left(\frac{\partial t_{i} k_{i}}{\partial t_{i}}+\frac{\partial s_{i}}{\partial t_{i}}\right)+\beta \sum_{\substack{m=1 \\
m \neq j}}^{n}\left(\frac{\partial t_{m} k_{m}}{\partial t_{i}}+\frac{\partial s_{m}}{\partial t_{i}}\right) \\
& \frac{\partial t_{i} k_{i}}{\partial t_{i}}+\frac{\partial s_{i}}{\partial t_{i}}+\beta(n-1)\left(\frac{\partial t_{j} k_{j}}{\partial t_{i}}+\frac{\partial s_{j}}{\partial t_{i}}\right)=(1+\beta(n-2))\left(\frac{\partial t_{j} k_{j}}{\partial t_{i}}+\frac{\partial s_{j}}{\partial t_{i}}\right)+\beta\left(\frac{\partial t_{i} k_{i}}{\partial t_{i}}+\frac{\partial s_{i}}{\partial t_{i}}\right) \\
& (1-\beta)\left(\frac{\partial t_{i} k_{i}}{\partial t_{i}}+\frac{\partial s_{i}}{\partial t_{i}}\right)=(1-\beta)\left(\frac{\partial t_{j} k_{j}}{\partial t_{i}}+\frac{\partial s_{j}}{\partial t_{i}}\right),
\end{aligned}
$$

where symmetry is applied in the second line. Substituting A.23, we get:

$$
(1-\beta) \frac{\partial s_{j}}{\partial t_{i}}=(1-\beta)\left(n \frac{\partial T}{\partial t_{i}}-(n-1) \frac{\partial s_{j}}{\partial t_{i}}+\frac{\partial t_{i} k_{i}}{\partial t_{i}}-\frac{\partial t_{j} k_{j}}{\partial t_{i}}\right)
$$

Solving for $\frac{\partial s_{i}}{\partial t_{i}}$ and $\frac{\partial s_{j}}{\partial t_{i}}$, results in the reaction functions

$$
\begin{aligned}
& (1-\beta) \frac{\partial s_{i}}{\partial t_{i}}=(1-\beta)\left(\frac{n-1}{n}\left(\frac{\partial t_{j} k_{j}}{\partial t_{i}}-\frac{\partial t_{i} k_{i}}{\partial t_{i}}\right)+\frac{\partial T}{\partial t_{i}}\right) \\
& (1-\beta) \frac{\partial s_{j}}{\partial t_{i}}=(1-\beta)\left(\frac{\partial T}{\partial t_{i}}+\frac{1}{n}\left(\frac{\partial t_{i} k_{i}}{\partial t_{i}}-\frac{\partial t_{j} k_{j}}{\partial t_{i}}\right)\right)
\end{aligned}
$$

which simplifies to 39 for $\beta<1$.

In stage 1 , the regional governments maximize regional utility incorporating the reaction of 
the federal policy to their tax increase:

$$
\begin{array}{r}
\max _{G_{i}, g_{i}, c_{i}, t_{i}} U\left(c_{i}, G_{i}\right) \quad g_{i}+\beta \sum_{\substack{m=1 \\
m \neq i}}^{n} g_{m} \\
g_{i}=t_{i} k_{i}+s_{i} \\
c_{i}=f\left(k_{i}\right)-f^{\prime}\left(k_{i}\right) k_{i}+\bar{k}_{i} R-T \\
t_{i} \geq 0 \\
s_{i}=s_{i}\left(t_{i}, t_{j}\right) ; \quad s_{j}=s_{j}\left(t_{i}, t_{j}\right) ; \quad T=T\left(t_{i}, t_{j}\right) .
\end{array}
$$

with

\section{Corollary 1}

In stage 2 , the maximization problem of the federal government using a gross transfer system as defined by part is is:

$$
\begin{array}{ll}
\max _{\left\{G_{1 \ldots n}\right\},\left\{s_{1 \ldots n}\right\},\left\{T_{1 \ldots n}\right\},\left\{g_{1 \ldots n}\right\},\left\{c_{1 \ldots n}\right\}} \sum_{i=1}^{n} U_{i}\left(c_{i}, G_{i}\right) \quad \text { s.t. } \quad G_{i}=g_{i}+\beta \sum_{\substack{m=1 \\
m \neq i}}^{n} g_{m} \\
& \sum_{i=1}^{n} s_{i}=\sum_{i=1}^{n} T_{i} \\
& g_{i}=t_{i} k_{i}+s_{i} \\
& c_{i}=f\left(k_{i}\right)-\frac{\partial f\left(k_{i}\right)}{\partial k_{i}} k_{i}+\bar{k}_{i} R-T_{i} .
\end{array}
$$

The Lagrangian and the FOCs are:

$$
\begin{aligned}
\max _{\left\{s_{1 \ldots n\},\left\{T_{1 \ldots n}\right\}} L=\right.} \sum_{i=1}^{n} U_{i}\left(f\left(k_{i}\right)-\frac{\partial f\left(k_{i}\right)}{\partial k_{i}} k_{i}+\bar{k}_{i} R-T_{i}, t_{i} k_{i}+s_{i}+\beta \sum_{\substack{m=1 \\
m \neq i}}^{n} t_{m} k_{m}+s_{m}\right) \\
\quad+\lambda\left(\sum_{i=1}^{n} s_{i}-\sum_{i=1}^{n} T_{i}\right) \\
\frac{\partial L}{\partial s_{i}}=\frac{\partial U}{\partial G_{i}}+\beta \sum_{m=1}^{n} \frac{\partial U}{\partial G_{m}}+\lambda=0 \quad \forall i \\
\frac{\partial L}{\partial T_{i}}=-\frac{\partial U}{\partial c_{i}}-\lambda=0 \quad \forall i \\
\frac{\partial L}{\partial \lambda}=\sum_{i=1}^{n} s_{i}-\sum_{i=1}^{n} T_{i}=0
\end{aligned}
$$


Combining will lead to the same optimality conditions as in 4.1.2, i.e. (33) and (34).

The problem for part iii, after substituting the budget constraints, is given by:

$$
\begin{aligned}
\max _{\left\{s_{1 \ldots n}\right\},\left\{\tau_{1 \ldots n}\right\}, T} L= & U_{i}\left(f\left(k_{i}\right)-\frac{\partial f\left(k_{i}\right)}{\partial k_{i}} k_{i}+\bar{k}_{i} R+\tau_{i}-T, t_{i} k_{i}+s_{i}+\beta \sum_{\substack{m=1 \\
m \neq i}}^{n} t_{m} k_{m}+s_{m}\right) \\
& +\sum_{\substack{j=1 \\
j \neq i}}^{n} U_{j}\left(f\left(k_{j}\right)-\frac{\partial f\left(k_{j}\right)}{\partial k_{j}} k_{j}+\bar{k}_{j} R+\tau_{j}-T, t_{j} k_{j}+s_{j}+\beta \sum_{\substack{m=1 \\
m \neq j}}^{n} t_{m} k_{m}+s_{m}\right) \\
& +\lambda\left(\sum_{i=1}^{n} s_{i}-n T\right) \\
& +\mu\left(\sum_{i=1}^{n} \tau_{i}\right)
\end{aligned}
$$

The first order conditions are given by:

$$
\begin{aligned}
& \frac{\partial L}{\partial s_{i}}=\frac{\partial U}{\partial G_{i}}+\beta \sum_{\substack{m=1 \\
m \neq i}}^{n} \frac{\partial U}{\partial G_{m}}+\lambda=0 \quad \forall i \\
& \frac{\partial L}{\partial T}=-\sum_{i=1}^{n} \frac{\partial U}{\partial c_{i}}-\lambda n=0 \\
& \frac{\partial L}{\partial \tau_{i}}=\frac{\partial U}{\partial c_{i}}+\mu=0 \quad \forall i \\
& \frac{\partial L}{\partial \lambda}=\sum_{i=1}^{n} s_{i}-n T=0 \\
& \frac{\partial L}{\partial \mu}=\sum_{i=1}^{n} \tau_{i}=0
\end{aligned}
$$

Combining leads to:

$$
\begin{array}{lll}
U^{\prime}\left(G_{i}\right)=U^{\prime}\left(G_{j}\right) & \Rightarrow G_{i}=G_{j} & \forall i, j, \\
U^{\prime}\left(c_{i}\right)=U^{\prime}\left(c_{j}\right) & \Rightarrow c_{i}=c_{j} & \forall i, j, \\
\frac{\frac{\partial U}{\partial G_{i}}}{\frac{\partial U}{\partial c_{i}}} \equiv M R S_{i}=\frac{1}{1+(n-1) \beta} & &
\end{array}
$$

in symmetry. Using A.30 for region $i$ and $j$ results in A.35). Likewise, using A.32 for $i$ and $j$ leads to A.36). Combining A.30 with A.31 establishes A.37). 
The federal government chooses transfers $s_{i}$ and $\tau_{i}$ such that the marginal utilities of private and public consumption across regions are equalized, which implies equal private and public good consumption across regions in symmetry. These two conditions suffice to establish an efficient solution as demonstrated in 4.1.2. The same is true if we concentrate on the firstorder condition for $T$ instead. Given that this problem has one redundant instrument, and that regions are ex-ante symmetric, the regional tax rates $t_{i}=t_{j}=t$ are not identified in this equilibrium. If regional taxes are doubled, then the transfers would simply be cut in half, leaving public and private consumption unchanged as defined by A.35)-A.37). Without loss of generality, we can therefore set $t_{i}$ to zero for all regions, or to any other value.

\section{A.3 Centralized leadership}

Starting in stage 2, the regional governments' problem is given by

$$
\begin{aligned}
\max _{G_{i}, g_{i}, c_{i}, t_{i}} & U_{i}\left(c_{i}, G_{i}\right) \\
\text { s. t. } & g_{i}=\frac{t_{i} k_{i}}{1-\alpha} \\
c_{i} & =f\left(k_{i}\right)-\frac{\partial f\left(k_{i}\right)}{\partial k_{i}} k_{i}+\bar{k}_{i} R-T \\
G_{i} & =g_{i}+\beta \sum_{\substack{m=1 \\
m \neq i}}^{n} g_{m} .
\end{aligned}
$$

The optimality condition from combining the first order conditions results in (A.2). When regional governments maximize regional utility, the marginal effect of taxes on consumption (income) is equivalent to the effect in the Nash game:

$$
\frac{\partial c_{i}}{\partial t_{i}}=-f^{\prime \prime}\left(k_{i}\right) \frac{\partial k_{i}}{\partial t_{i}} k_{i}+\frac{\partial R}{\partial t_{i}} \bar{k}_{i}
$$

The marginal effect of taxes on public consumption is given by:

$$
\frac{\partial G_{i}}{\partial t_{i}}=\frac{1}{1-\alpha}\left(k_{i}+t_{i} \frac{\partial k_{i}}{\partial t_{i}}+\beta \sum_{\substack{m=1 \\ m \neq i}}^{n} \frac{\partial t_{m} k_{m}}{\partial t_{i}}\right) .
$$

Using A.38 and A.39 in the $M R S$ A.2 gives 


$$
M R S_{i}^{C E}=\frac{f^{\prime \prime}\left(k_{i}\right) \frac{\partial k_{i}}{\partial t_{i}} k_{i}-\frac{\partial R}{\partial t_{i}} \bar{k}_{i}}{\frac{1}{1-\alpha}\left[k_{i}+\frac{\partial k_{i}}{\partial t_{i}} t_{i}\right]+\beta \sum_{\substack{m=1 \\ m \neq i}}^{n} \frac{\partial k_{m}}{\partial t_{i}} t_{m}} .
$$

In symmetry and incorporating the reaction of the capital market given by 10, A.40 becomes the optimality condition for the regions' problem:

$$
M R S^{C E}=\frac{1-\alpha}{1+(1-\beta)\left(\frac{n-1}{n}\right) \frac{1}{f^{\prime \prime}(k)} \frac{t}{k}} .
$$

In stage 1, substituting all budget constraints (households, regional and federal governments) and the definition for $G_{i}$, the federal government chooses $\alpha$ to maximize

$$
\max _{\alpha} \sum_{i=1}^{n} U_{i}\left(f\left(k_{i}\right)-\frac{\partial f\left(k_{i}\right)}{\partial k_{i}} k_{i}+\bar{k}_{i} R-\frac{\alpha}{n} \sum_{i=1}^{n} g_{i} ; \frac{t_{i} k_{i}}{1-\alpha}+\beta \sum_{\substack{m=1 \\ m \neq i}}^{n} \frac{t_{m} k_{m}}{1-\alpha}\right),
$$

which is

$$
\begin{aligned}
& \frac{\partial U_{i}}{\partial c_{i}} \sum_{i=1}^{n}\left(-\frac{1}{n} \frac{t_{i} k_{i}}{1-\alpha}-\frac{\alpha}{n} \frac{t_{i} k_{i}}{(1-\alpha)^{2}}\right)+\frac{\partial U_{i}}{\partial G_{i}}\left(\frac{t_{i} k_{i}}{(1-\alpha)^{2}}+\beta \sum_{\substack{j=1 \\
j \neq i}}^{n} \frac{t_{j} k_{j}}{(1-\alpha)^{2}}\right) \\
& +\sum_{\substack{j=1 \\
j \neq i}}^{n} \frac{\partial U_{j}}{\partial c_{j}} \sum_{j=1}^{n}\left(-\frac{1}{n} \frac{t_{j} k_{j}}{1-\alpha}-\frac{\alpha}{n} \frac{t_{j} k_{j}}{(1-\alpha)^{2}}\right)+\sum_{\substack{j=1 \\
j \neq i}}^{n} \frac{\partial U_{j}}{\partial G_{j}} \frac{t_{j} k_{j}}{(1-\alpha)^{2}}+\beta \sum_{\substack{m=1 \\
m \neq j}}^{n} \frac{t_{m} k_{m}}{(1-\alpha)^{2}}=0 .
\end{aligned}
$$

Multiplying by $\frac{1}{(1-\alpha)^{2}}$, simplifying, imposing symmetry and collecting terms gives us in symmetry:

$$
M R S^{C E}=\frac{1}{1+(n-1) \beta}=M R S^{P O} .
$$

which is equivalent to the social optimum in (14).

\section{Proof of Proposition 4:}

(i) When treating $s_{i}$ as a lump-sum transfer rather than a matching grant, the transfer drops out of regions' first-order conditions, and the resulting equilibrium is characterized by expression (21) and thus identical to the Nash equilibrium.

(ii) In order to induce Pareto-efficiency, the federal government sets the matching rate $\alpha$ such 
that $\mathrm{A} .41$ ) and $\mathrm{A.43}$ are equalized:

$$
\frac{1-\alpha}{1+(1-\beta)\left(\frac{n-1}{n}\right) \frac{1}{f "(k)} \frac{t}{k}}=\frac{1}{1+(n-1) \beta} .
$$

Solving for $\alpha$ results in

$$
\begin{aligned}
\alpha^{C E} & =\frac{n-1}{n} \cdot \frac{n \beta+(1-\beta) \frac{1}{-f^{\prime \prime}(k)} \frac{t}{k}}{1+(n-1) \beta} \\
& =\frac{(n-1) \beta+(1-\beta) \epsilon}{1+(n-1) \beta},
\end{aligned}
$$

with $\epsilon \equiv \frac{n-1}{n} \frac{1}{-f^{\prime \prime}\left(k_{i}\right)} \frac{t}{k}$

(iii) The derivative of the matching rate w.r.t. the spillover parameter is given by:

$$
\frac{\partial \alpha^{C E}}{\partial \beta}=\frac{(n-1)\left(1+\frac{1}{f^{\prime \prime}(k)} \frac{t}{k}\right)}{(1+(n-1) \beta)^{2}} .
$$

Provided that $n>1$, it follows that for $\frac{1}{\left|f^{\prime \prime}(k)\right|} \frac{t}{k}<1, \partial \alpha^{C E} / \partial \beta>0$, and vice versa. 